\title{
¿NEOLIBERALISMO? \\ EL CRECIMIENTO DE LA MATRÍCULA DE LA EDUCACIÓN PRIVADA EN ARGENTINA Y URUGUAY
}

\section{NEOLIBERALISM? \\ THE GROWTH OF PRIVATE EDUCATION IN ARGENTINA AND URUGUAY}

\author{
Mariano Narodowski* \\ mnarodowski@utdt.edu \\ Carolina Snaider** \\ carolinasnaider@hotmail.com
}

\begin{abstract}
Resumen
Durante las últimas tres décadas, se evidencia para la mayoría de los países latinoamericanos el crecimiento de la matrícula escolar gestionada desde el sector privado. Para muchos estudiosos del tema, es el perfil llamado "neoliberal" el que se traduce en el campo de los sistemas educativos dando cuenta de ese incremento. Tomando como casos a la Argentina y al Uruguay, este estudio se propone discutir la teoría predominante que en estos años ha construido al neoliberalismo como la llave explicativa del aumento de la educación privada, analizando evidencia estadística de la matrícula en ambos países y poniéndola en relación con los diferentes ciclos macropolíticos que se han ido atravesando.
\end{abstract}

Palabras Clave: Educación privada, educación pública, neoliberalismo.

\begin{abstract}
During the last three decades, the majority of Latin American countries have displayed a growth in private education enrolment. For many researchers in the field, it is "neoliberalism" translated to the educational systems that explains this rise. Examining the cases of Argentina and Uruguay, the purpose of this study is to discuss the prevailing theory that has posited neoliberalism as the explanatory key in private education growth; the statistic enrolment evidence is analyzed in both countries in relation to the various macro-political cycles that they have been undergoing.
\end{abstract}

Keywords: Private Education, Public Education, Neoliberalism.

\footnotetext{
* Profesor de la Universidad Torcuato Di Tella. Sus áreas de interés son los estudios sobre el pasado y el futuro de la infancia y los sistemas educativos comparados. Ha publicado 20 libros y decenas de artículos académicos en revistas como Journal of Education Policy, Compare, Discoursse, entre otros.

** Magister en Educación, Investigadora asistente, Universidad Torcuato Di Tella.
} 


\section{Comparando Argentina y Uruguay}

Durante las últimas tres décadas, el debate educacional latinoamericano se vio atravesado por la cuestión de la privatización de la educación. Desde los medios de comunicación, los posicionamientos políticos y sindicales (especialmente de los sindicatos docentes) y desde el ámbito académico, diferentes estudios e investigaciones que indagaban acerca del devenir de los sistemas educativos en América Latina advertían respecto de la posibilidad concreta de un aumento de la matrícula de la educación privada como efecto de un conjunto de políticas educativas que visualizan en el proceso de privatización de la educación una matriz adecuada para resolver los problemas educacionales de la región. El término "neoliberalismo" ha ocupado, en estos años, un lugar central en la explicación de los fenómenos aludidos (Torres y Puiggrós, 1995:9; Puiggrós, 2003:190; López Guerra y Chávez, 2009:1065).

Frente a estas dos cuestiones que han corrido en paralelo -el crecimiento de la educación privada que se evidencia en la mayoría de los países latinoamericanos y la recurrencia al concepto de "neoliberalismo" como su llave explicativa-, el objetivo del presente artículo es buscar comprender las articulaciones existentes entre la lógica de este proceso de privatización y las explicaciones presentes en el plano teórico. Tomando como casos a la Argentina y al Uruguay, este estudio se propone discutir la teoría predominante que en estos años ha construido al neoliberalismo como el dispositivo explicativo nodal a la luz de la evidencia estadística del crecimiento de la matrícula privada (en los niveles primario y secundario de la educación común) en ambos países, en relación con los diferentes ciclos macropolíticos que atravesaron.

La elección de Uruguay y Argentina como términos y objetos de este estudio comparado se justifica por varias razones. En primer lugar, ambos pertenecen al continente sudamericano y están atravesados por una historia política y cultural común, historia no exenta de enfrentamientos y conflictos (incluso bélicos) pero que engarza una afinidad notoria, especialmente en lo relativo a la región litoral Paraná, Uruguay y rioplatense. Es verdad que ambos países difieren entre sí en la extensión territorial, en su número de habitantes, en el tamaño de su PBI, y -como veremos luego

$:: 50::$ con mayor profundidad- en la organización político institucional, incluido su sistema educativo. Sin embargo, entendemos que a pesar de las disimilitudes (y siempre siendo cuidadosos en los análisis) el proceso de comparación es absolutamente factible.

Por otro lado, Argentina y Uruguay comparten una historia común bastante similar en lo que respecta a los orígenes y primeros desarrollos de su educación pública, especialmente en lo relativo a la educación primaria a finales del siglo XIX y a los éxitos logrados por ambos sistemas educativos en la primera mitad del siglo XX (CEPAL, 1990: 5; Ossenbach Sauter, 2001:8).

Bajo la advocación de las figuras paradigmáticas de Domingo Faustino Sarmiento y de José Pedro Varela, las sociedades argentina y uruguaya construyeron, respectivamente, un relato de educación pública democrática e igualitaria. Promotora de ascenso social, en ambas naciones mantuvo el liderazgo americano por décadas. Una escuela pública dominante, probablemente monopólica que durante más de 50 años gozó del consenso y la legitimidad social en los dos países (Martínez Boom y Narodowski, 1996: 12; Fernández Aguerre, 2002: 504).

Pero también, en los dos países es posible encontrar los dos fenómenos recurrentes que se pretende enlazar en el presente estudio: un aumento muy significativo de la matrícula de la educación privada por un lado y la presencia de las denominadas "políticas públicas neoliberales" en varios de los ciclos políticos recientes. En función de esto, y como ya hemos mostrado en estudios previos (Narodowski y Moschetti, 2015:2), los sistemas educativos latinoamericanos (y especialmente el del Uruguay y el de la Argentina), ofrecen un singular escenario para contrastar con la evidencia estadística al corpus de explicaciones que muchos autores han encontrado entre neoliberalismo y privatización de la educación en América Latina. Es que durante los años noventa del siglo XX, las políticas económicas y educativas han sido caracterizadas como de "neoliberales" por buena parte de la opinión pública y de la producción académica mientras que las que fueron consecuencia de los gobiernos surgidos en ambos países en los años dos mil (el encabezado por el kirchnerismo en la Argentina y por el Frente Amplio en el Uruguay) se han posicionado como fuerzas gubernamentales explícitamente opositoras al neoliberalismo, pregonando una matriz ideológica diferente e incluso 
tendiendo a desactivar algunos de los dispositivos políticos, administrativos y regulatorios que respaldaron la matriz política-ideológica de la denominada "experiencia neoliberal" previa en cada país. Este abrupto contraste entre el "neoliberalismo" hasta la primera mitad de los dos mil y el explícito "antineoliberalismo" en los gobiernos posteriores refuerza la variable macropolítica de un escenario excelente para este estudio.

Por este motivo, el análisis de la evolución de los principales indicadores vinculados a la privatización de la educación en ambos países para estas últimas dos décadas habrá de conformar un panorama razonable para contrastar las afirmaciones de estos estudios recién reseñados que ven en América Latina una intrincada relación entre neoliberalismo y privatización de la educación (en el sentido de un crecimiento sostenido de la educación privada) o, acaso, para seguir confirmando otros posicionamientos teóricos que vienen advirtiendo- especialmente para el caso argentino- que la tendencia privatizadora es muy anterior al llamado "auge neoliberal" (Narodowski, 2002: 22) y que su relevancia creciente se explica menos por el efecto de políticas públicas coyunturales o proclamas ideológicas de época y más por la propia dinámica de crecimiento del sistema educativo en contextos de colapso (o como mínimo de crisis) de los recursos fiscales destinados a la educación (Narodowski, 2010: 38).

La hoja de ruta del presente artículo prosigue de inmediato con la descripción de los argumentos de los principales autores que abonan la idea de que la privatización de la educación es una consecuencia del neoliberalismo. Posteriormente, se exponen datos de escolarización en la Argentina y en el Uruguay, relativos al nivel primario y al medio de la educación común, que marcan un pronunciado incremento de la participación de la matrícula escolar privada sobre el total, indagando también sobre las diferencias y similitudes provinciales/departamentales en su comportamiento. En la cuarta sección se analizan regulaciones e incentivos financieros estatales y privados en ambos países para la elección de escuela privada. Finalmente, se articula la evidencia estadística obtenida con los ciclos macropolíticos de gobierno de cada país con el objeto de sopesar el comportamiento de cada una de las variables. En las conclusiones se evalúan las limitaciones del uso del concepto "neoliberalismo" como llave explicativa para los casos estudiados y se proponen algunas vías específicas para estudios futuros.

\section{Neoliberalismo y privatización de la educación en América Latina}

Como ya hemos planteado en trabajos previos (Narodowski y Nores 2003: 2; Narodowski y Moschetti, 2015: 2 ), a pesar de lo generalizado de su uso, el término 'neoliberalismo' no parece haber resultado del todo preciso en la caracterización del rumbo que ha adoptado las políticas públicas -especialmente en materia educacional- en los últimos treinta años. Aún admitiendo que se presenta como un concepto que adquiere múltiples significados y que, llamativamente, no existan actores políticos, académicos o mediáticos que se atribuyan como propia esta doctrina (es decir, nadie afirma "soy neoliberal") lo cual predispone a pensar que "neoliberalismo" parece más un epíteto que el nombre de una corriente en la economía o las ciencias sociales, es posible conjeturar que, al menos como regla general y mayoritaria, se lo ha pretendido definir como un movimiento económico, político y cultural contrapuesto a las políticas del estado de bienestar y que, como tal, otorga primacía al mercado en la regulación del comportamiento de los actores (Giroux, 2005:1).

Su surgimiento parece atribuible históricamente a los planteos teóricos de mediados de siglo XX por parte de Friedrich von Hayek (1994: 45) y especialmente de Milton Friedman(2002: 11). Sin embargo, es recién hacia fines de la década de 1970 cuando comienza a evidenciarse un cambio de rumbo en las políticas conducidas por los estados en ese nuevo sentido y a difundirse sus ideas-fuerza por fuera de ámbitos especializados, popularizándose en los medios de comunicación algunos de sus slogans vinculados al "estado mínimo" y a la "eficiencia del sector privado", entre otros.

Siguiendo la descripción de Klees (2008: 312), la política económica neoliberal supone una serie de reformas interrelacionadas: "estabilidad macro-económica; recorte de los presupuestos públicos; privatización de las operaciones gubernamentales; fin a las tarifas y otras formas de medidas proteccionistas; facilitación del movimiento de capitales extranjeros, fomento de las exportaciones, 
cobro de tarifas para muchos servicios públicos y disminución de las protecciones al trabajador mediante la flexibilización del los mercados laborales"1. Estas reformas generales en el Estado y el mercado, se tiende a inferir, tienen un correlato directo en la organización de los sistemas educativos.

Algunos autores han tendido a destacar que la privatización de la educación no es solamente una consecuencia de reformas neoliberales macro sino mucho más: puede llegar a constituir incluso una causa o, al menos, un relevante factor interviniente: el campo educativo constituyó un sector clave para el impulso de las reformas neoliberales aun habiendo encontrado allí gran resistencia para su puesta en marcha (Small, 2009: 3; Lipman, 2011: 1). ¿Cuáles son los indicadores más significativos de la presencia de una política educativa neoliberal o, simplemente, de "neoliberalismo educativo"? Klees destaca tres direcciones que ha adoptado el pensamiento y la acción neoliberal en el ámbito de la educación: "el incremento de cobro de aranceles a los usuarios, la mayor privatización de actividades educativas, y la conexión directa entre gestión y financiamiento de la educación con la medición de resultados" (2008: 312).

Como se ve, las primeras dos direcciones están directamente vinculadas al incremento de la oferta educacional privada (arancelada y eventualmente con fines de lucro) mientras que la tercera se vincula a la incorporación de una cultura escolar de tipo "managerialista" -en contraste con las tradiciones pedagógicas- (Ball, 2009: 85) y de vinculación de insumos financieros con resultados medibles a fin de hacer más eficiente al sistema escolar. Como señala el último autor, estas líneas de política rompen con el paradigma de las décadas previas a 1980 cuando la educación era asumida como una responsabilidad casi enteramente pública y estatal por lo que es posible concluir la existencia de un cambio en el rol del Estado que pasará a ser "contratista, monitor y evaluador de servicios prestados por una amplia gama de proveedores" (Ball y Youdell, 2008: 80). Small, por su parte, va muchos más lejos todavía dado que postula que, por la preeminencia del mercado en la toma de decisiones educacionales, "el modelo democrático social de la educación no tiene lugar en el nuevo mundo del neoliberalismo" (2009: 1).

$:: 52::$ La cuestión es que las reformas neoliberales en educación que han recibido mayor atención la constituyen las políticas impulsoras de alguna variante de privatización. Estas políticas se enmarcan en un proceso que algunos señalan como de 'desestatalización' (Jessop, 2002: 199,) en virtud de lo que evidencian como un "retiro del Estado" respecto de sus funciones tradicionales. Ball y Youdell (2008: 74) destacan en este sentido dos formas específicas de privatización educacional. Por un lado, la denominada privatización exógena, o 'privatización de la educación', donde el estado habilita e incentiva la participación del sector privado en la provisión de servicios educativos públicos. Por otro lado, la privatización endógena, o 'privatización en la educación', que supone "la importación de ideas, técnicas y prácticas del sector privado a fin de asimilar el sector público al sector empresarial". Similares enfoques suelen denominar a esta variante como 'comercialización' (Ball, 2008: 87), o 'corporatización' de la educación (Saltman, 2009: 9). Como veremos, los casos argentino y uruguayo se corresponden con la primera de las formas enumeradas, siendo que la segunda prácticamente no ha tenido incidencia significativa en ambos países.

Según Ball y Youdell, no resulta habitual que las políticas tendientes a privatizar los servicios educativos, ya sea de forma endógena o exógena, sean articuladas en términos de privatización propiamente. Por el contrario, los gobiernos han preferido hacer referencia a términos como 'elección de escuela', 'rendición de cuentas', 'mejora escolar, 'devolución', 'competitividad' o 'eficacia' (2008: 73). Small (2009: 8) y Ball y Youdell (2008: 80) coinciden en que independientemente del modo en que sean nombradas las reformas, y lejos de ser "tan solo cambios técnicos en la forma en que se provee educación" (Ball y Youdell, 2008: 79), todas conllevan y construyen una nueva "moral de mercado' donde la educación atraviesa un proceso de 'mercantilización' "a través del cual [la educación] pasa a ser considerada únicamente en términos de su valor de cambio más que por su valor intrínseco o sus fines sociales" (Ball y Youdell, 2008: 80). 
Para el caso de la traducción de estos ejes relativos a la privatización de la educación para los países latinoamericanos, existe en la literatura académica una idea bastante generalizada de que las reformas neoliberales en educación resultaron de la exigencias planteadas en ese sentido por los organismos de crédito internacionales: el Banco Mundial, el Fondo Monetario Internacional y, en menor medida, el Banco Interamericano de Desarrollo (Puiggrós, 1996: 6; Torres y Puiggrós, 1995: 7 López Guerra y Flores, 2009: 1068; Torres, 2008: 217). Así, para no pocos estudiosos fueron trazadas como necesarias "la descentralización y privatización de los sistemas, la flexibilización de la contratación, la piramidización y la reducción de la planta docente y un fuerte control de los gobiernos nacionales mediante la imposición de contenidos y evaluaciones comunes" (Puiggrós, 1996: 2). La justificación para impulsar la reconversión del rol del estado ha sido, según Puiggrós, la caracterización de los sistemas escolares tradicionales como "ineficientes, inequitativos y sus productos de baja calidad" (Puiggrós, 1996: 1). En un contexto donde efectivamente los sistemas educativos requerían modificaciones y ante la ausencia de propuestas alternativas, las reformas neoliberales habrían así encontrado un terreno fértil en América Latina (Puiggrós, 1996: 2).

Con este mismo enfoque Torres (2008: 219), precisa las tres dimensiones en las que el neoliberalismo tuvo impacto directo en las políticas educativas de la región latinoamericana: "en la economía política del financiamiento educativo; en las vinculaciones entre educación y trabajo; y en la creación de estándares de excelencia académica internacional, con sus implicancias a nivel de evaluación, currículum, educación superior o formación docente". Hacia estas tres dimensiones han sido dirigidas desde las reformas que impulsaron cambios en las formas y/o destinatarios del financiamiento estatal (privatización, vouchers, charters), hasta aquellas que han pretendido configurar un Estado 'evaluador'. En este sentido, es la visión de muchos autores de estos autores que en Latinoamérica, el problema de la calidad educativa quedó reducido, en la agenda neoliberal, a un problema de gestión (López Guerra y Flores, 2006: 3).

Si bien estas referencias terminan por corroborar cuán ambiguo es el uso del término neoliberalismo, realmente no deja de sorprender su uso extendido en la literatura académica, tan lejos de una caracterización rigurosa. De hecho, en el plano de las políticas públicas, conceptos como "economía neoclásica" o "enfoque neoinstitucionalista" podrían encuadrar las argumentaciones referidas de manera una más austera y severa, aportando mayor claridad conceptual. Sin embargo, y como no es la intención aquí deconstruir el concepto de "neoliberalismo", si queda claro, como mínimo, que para el caso de América Latina, la privatización de la educación, el aumento relevante de matrícula en el sector privado y el consecuente "retiro del Estado" -en la medida que la iniciativa privada toma cuenta de lo que venía realizando el Estado- deben ser interpretados como epifenómenos de una tendencia más general que el concepto de "neoliberalismo", según estos autores y estos enfoques tan generalizados, está llamado a explicar.

\section{El comportamiento de la matrícula de educación pública y privada}

\section{a) El caso de la Argentina}

Ya desde su Constitución Nacional de 1853, aunque especialmente a partir de las reformas de 1991, Argentina es un país con un sistema educativo federal, similar a Brasil, Estados Unidos o Canadá. El gobierno nacional financia y orienta algunos programas de políticas educativas pero de su Ministerio de Educación de la Nación no depende ninguna escuela en forma directa. Al contrario, cada escuela está en manos -para su financiamiento y regulación- de cada una de las 24 jurisdicciones nacionales; 23 son provincias y una es la Ciudad Autónoma de Buenos Aires, la Capital Federal del país.

Para el caso argentino, a partir de los años sesenta del siglo XX, es muy visible el incremento de la matrícula de la educación privada. Como mostramos en estudios anteriores (Narodowski y Andrada, 2001: 586; Narodowski y Moschetti, 2015: 6), el incremento de la población que asiste a escuela privada ha sido sostenido en los últimos cincuenta años aunque los datos que habremos de exponer reflejan también que en los últimos 20 años el crecimiento se ha incrementado y se mantiene en forma consistente a lo largo del tiempo. 
Ésta tendencia creciente general de la educación privada en el país se demuestra el Grafico № 1.

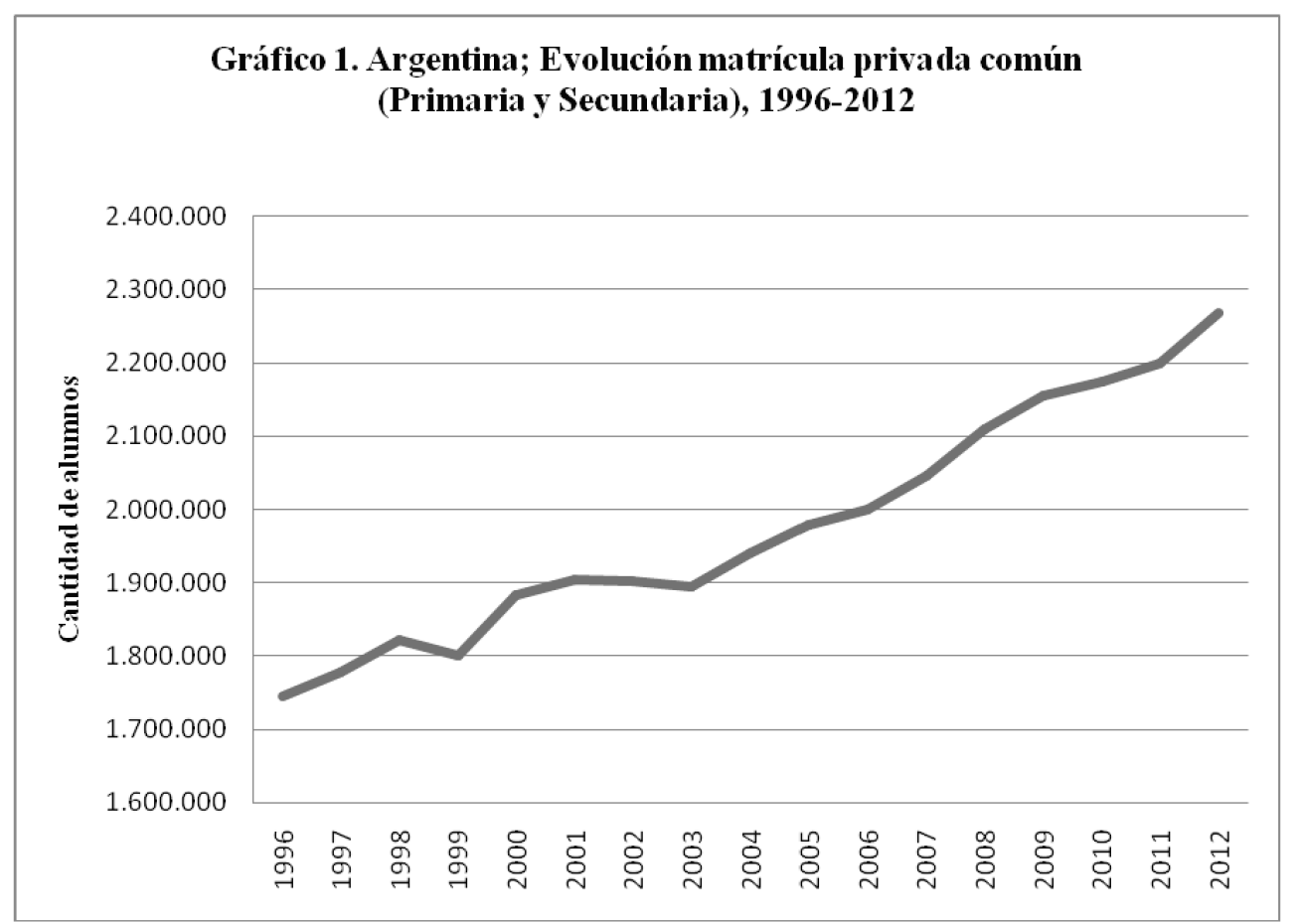

Fuente: Elaboración propia en base a Argentina, Ministerio de Educación, DiNIECE.

El crecimiento de la matrícula de la educación privada estuvo, a su vez, acompañado por un incremento de su participación sobre el total de los alumnos del sistema educativo. Al observar el ::54:: Gráfico № 2 puede corroborarse cómo la curva que marca esta participación es levemente a la baja hasta el año 1999, para luego comenzar a ascender y llegar al 2012 (el último dato oficial disponible) con el $26,94 \%$ de participación de la matrícula privada sobre el total, siempre tomando la educación primaria y secundaria común.

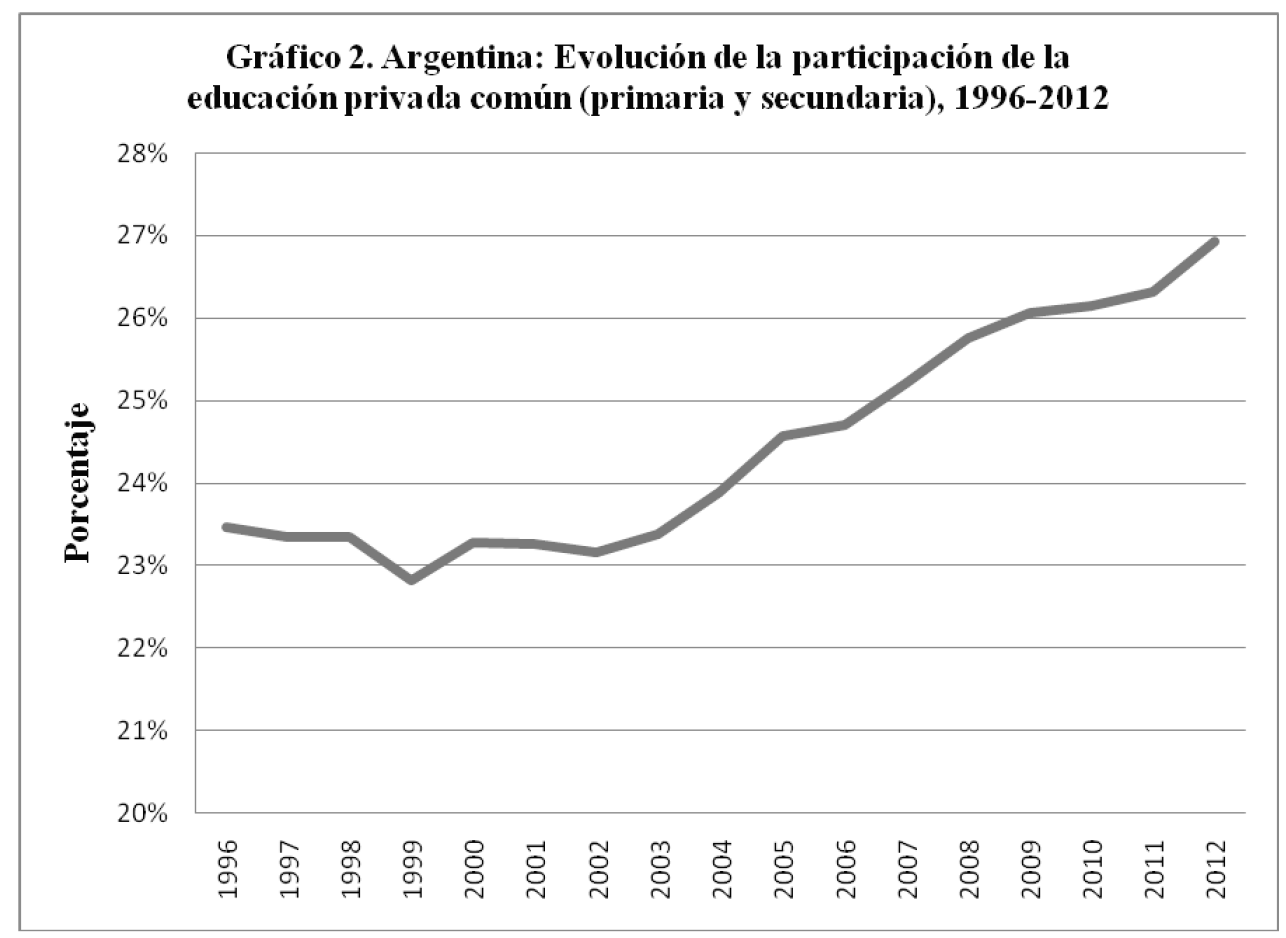

Fuente: Elaboración propia en base a Argentina, Ministerio de Educación, DiNIECE. 
Al igual que en el resto de los países latinoamericanos, Argentina presenta una estructura socioeconómica fuertemente desigual y la misma se ve también reflejada en su estructura federal, con provincias con un grado significativo de desarrollo económico y con provincias muy empobrecidas. Para ser ilustrativos, mientras la Ciudad Autónoma de Buenos Aires observa un producto PBI per cápita superior a 14.000 dólares para mediados de la década de los dos mil, la provincia de Jujuy, en el extremo noroeste del país, en la frontera con Bolivia y Chile, tiene un PBI per cápita de 2.404 dólares (CENM, 2007: 1).

Contrariamente a lo que estas significativas diferencias socioeconómicas pudieran invitar a suponer respecto del comportamiento de la matrícula del sector privado, su tendencia creciente no presenta variaciones en demasía entre unas y otras jurisdicciones. Si se observan en el Cuadro №1 las tasas de crecimiento de la matrícula de la educación privada para el período 1996-2012 se podrá concluir que el crecimiento en relación con el crecimiento de alumnos en la escuela pública es significativo en todas las jurisdicciones.

Cuadro $N^{\circ}$ 1: Argentina. Crecimiento de la matrícula según jurisdicción y sector de gestión, 1996-2012. (Jurisdicciones ordenadas por PBG)

\begin{tabular}{|l|l|l|l|l|}
\hline Jurisdicción & $\begin{array}{l}\text { Crecimiento } \\
\text { Privada }\end{array}$ & $\begin{array}{l}\text { Crecimiento } \\
\text { Estatal }\end{array}$ & $\begin{array}{l}\text { Crecimiento } \\
\text { Total }\end{array}$ & $\begin{array}{l}\text { Privada } \\
\text { vs } \\
\text { Estatal }\end{array}$ \\
\hline Buenos Aires & $38,78 \%$ & $6,25 \%$ & $15,61 \%$ & $32,52 \%$ \\
\hline C.A.B.A. & $-0,25 \%$ & $-7,59 \%$ & $-4,24 \%$ & $7,34 \%$ \\
\hline Santa Fe & $6,96 \%$ & $-2,88 \%$ & $-0,27 \%$ & $9,85 \%$ \\
\hline Córdoba & $16,73 \%$ & $7,91 \%$ & $10,59 \%$ & $8,81 \%$ \\
\hline Neuquén & $58,57 \%$ & $4,10 \%$ & $8,51 \%$ & $54,47 \%$ \\
\hline Mendoza & $34,73 \%$ & $3,58 \%$ & $8,28 \%$ & $31,14 \%$ \\
\hline Entre Ríos & $24,47 \%$ & $6,12 \%$ & $10,07 \%$ & $18,35 \%$ \\
\hline Misiones & $45,29 \%$ & $16,04 \%$ & $20,33 \%$ & $29,25 \%$ \\
\hline $\begin{array}{l}\text { Santiago del } \\
\text { Estero }\end{array}$ & $54,62 \%$ & $13,71 \%$ & $18,51 \%$ & $40,91 \%$ \\
\hline Corrientes & $59,14 \%$ & $5,32 \%$ & $10,38 \%$ & $53,82 \%$ \\
\hline Río Negro & $37,80 \%$ & $1,76 \%$ & $6,90 \%$ & $36,04 \%$ \\
\hline Chaco & $69,89 \%$ & $20,54 \%$ & $23,90 \%$ & $49,35 \%$ \\
\hline Tucumán & $18,03 \%$ & $26,36 \%$ & $24,48 \%$ & $-8,32 \%$ \\
\hline Chubut & $23,23 \%$ & $17,52 \%$ & $18,20 \%$ & $5,72 \%$ \\
\hline Santa Cruz & $83,72 \%$ & $43,60 \%$ & $49,01 \%$ & $40,13 \%$ \\
\hline Salta & $42,64 \%$ & $19,07 \%$ & $22,32 \%$ & $23,57 \%$ \\
\hline San Luis & $53,11 \%$ & $33,18 \%$ & $35,60 \%$ & $19,93 \%$ \\
\hline San Juan & $77,97 \%$ & $10,87 \%$ & $19,88 \%$ & $67,10 \%$ \\
\hline Jujuy & $78,58 \%$ & $0,51 \%$ & $6,99 \%$ & $78,07 \%$ \\
\hline La Pampa & $65,24 \%$ & $3,35 \%$ & $10,28 \%$ & $61,89 \%$ \\
\hline $\begin{array}{l}\text { Tierra del } \\
\text { Fuego }\end{array}$ & $161,24 \%$ & $23,85 \%$ & $42,26 \%$ & $137,39 \%$ \\
\hline Catamarca & $109,43 \%$ & $9,50 \%$ & $19,14 \%$ & $99,93 \%$ \\
\hline La Rioja & $71,30 \%$ & $23,34 \%$ & $27,40 \%$ & $47,96 \%$ \\
\hline Formosa & $67,20 \%$ & $14,79 \%$ & $18,12 \%$ & $52,41 \%$ \\
\hline Total País & $29,95 \%$ & $8,13 \%$ & $13,25 \%$ & $21,82 \%$ \\
\hline
\end{tabular}

Fuente: Elaboración propia en base a Argentina, Ministerio de Educación, DiNIECE.

Como puede observarse, en todas las provincias argentinas -con las únicas excepciones de la Provincia de Tucumán y la Ciudad Autónoma de Buenos Aires- para la serie abarcada, la matrícula de la educación privada ha tenido un incremento bien mayor que la matrícula de la educación pública. El caso de la provincia de Tucumán el fenómeno puede deberse al muy bajo nivel socioeconómico de la población, aunque futuros estudios deberían investigar el tema con mayor detalle y rigor. El caso de la Ciudad de Buenos Aires es el inverso y los motivos de la situación ya han sido estudiados 
(Narodowski, Gonzalez Rozada, Gottau y Moschetti, 2014: 6): el proceso de privatización hubo de ocurrir mucho antes (especialmente en los años 80 del siglo XX) y el $50 \%$ de la matrícula en escuelas privadas parece mostrar un cierto techo, o al menos un punto de equilibrio, en las posibilidades de expansión del sector privado. Por otra parte, el mismo estudio muestra que la Ciudad enfrenta un amesetamiento en su crecimiento demográfico y un envejecimiento de su población lo que hace que caigan los valores absolutos de toda la matrícula escolar, aunque la de la escuela pública cae más que la de la escuela privada.

Pero es importante señalar que no solo la educación privada crece en casi en la totalidad de las provincias; como muestra el Cuadro $\mathrm{N}^{\circ} 1$, tampoco se encuentra relación entre el nivel de dicho crecimiento y el nivel de desarrollo económico en cada jurisdicción.

Es llamativo que en algunos casos la educación privada crece más que el total -y obviamente que la educación pública-. Este diferencial favorable al sector privado puede deberse a varios motivos. En primer lugar, es altamente probable que se produzcan muchos más pases de las escuelas públicas a las privadas que de las privadas a las públicas ya que apenas se producen unos pocos casos de la inversa de lo aquí analizado (es decir, que aumente más la matricula estatal que la privada). De hecho, este efecto sólo se produjo en algunas provincias durante la gran crisis económica del 2001-2002, además del ya señalado caso de la provincia de Tucumán. En segundo lugar, es muy posible, sea por el perfil socioeconómico de la población, sea por motivos pedagógicos, que la escuela pública tenga una menor capacidad de retención A modo de ilustración, los datos de la cohorte 2006-2011 para la secundaria estatal demuestran que más de la mitad de los jóvenes que ingresaron a la escuela media estatal no se graduaron en los términos esperados disminuyendo la matrícula en más de un $54 \%$. En contraste, durante el mismo período la escuela secundaria privada disminuyó su matrícula en valores- si bien elevados- considerablemente menores: aproximadamente un $22 \%$. En conclusión; el drop out se produce, mayoritariamente, en la educación pública. En el nivel secundario, por ejemplo, la tasa de abandono llega a ser, en algunas provincias, hasta cinco veces superior en el sector estatal (Narodowski, y Alegre, 2013: 8).

::56:: Como lógica contrapartida, la matrícula en escuelas públicas crece mucho menos que en escuelas privadas: para todo el país, mientras la matrícula privada aumenta en un $29,95 \%$ para el mismo período la educación pública apenas llega al $8.13 \%$. El único caso en que la cantidad de alumnos asistiendo a establecimientos de gestión pública aumenta en mayor medida que el aumento en el sector privado es el ya señalado caso de la Provincia de Tucumán.

Se destacan los casos singulares de la Ciudad Autónoma de Buenos Aires y Santa Fe, jurisdicciones que tienen una gran cantidad de habitantes: son casos en que se asiste a una disminución de la matrícula pública $(7.59 \%$ y $2.88 \%$ respectivamente). Por el lado de Santa Fe, mientras la escuela estatal pierde alumnos, la privada gana, presentando un aumento para el período analizado de $6,29 \%$. Asimismo, sobresalen provincias en las que el crecimiento de la educación privada ha sido de una magnitud considerable: Tierra del Fuego 161,24\% y Catamarca 109,43\%, seguidas por Santa Cruz, con un aumento del 83,72\%.

Es de observar que la educación primaria pública viene perdiendo, desde 2003 , un $7 \%$ de sus alumnos mientras que la educación privada ha ganado el $20 \%$ de incremento para el mismo período (Narodowski y Moschetti, 2015: 8, 2014: 1). En resumen, los datos de matrícula de la Argentina muestran un muy significativo crecimiento de la educación privada, tanto en valores absolutos como relativos: Hay cada vez más familias que envían a sus hijos a escuelas gestionadas desde el sector privado, a la vez que dicho sector crece a un ritmo mayor que el sector público resultando en un incremento de su participación porcentual sobre el total de alumnos del sistema. Además, este incremento de alumnos en escuelas privadas se refleja en prácticamente todas las provincias argentinas: aunque con disímiles tasas de crecimiento, el aumento de matrícula privada opera en casi todos los casos, con independencia de las virtuales diferencias socioeconómicas entre jurisdicciones. Estos datos conforman una tendencia que se da para todo el período estudiado y confirma lo ya señalado en estudios anteriores (Moschetti, 2012: 38; Narodowski y Andrada, 2001: 588, Narodowski y Moschetti, 2015: 8, entre otros). 


\section{b) El caso del Uruguay}

Por el lado de Uruguay- país limítrofe con la Argentina- la administración de la educación se gestiona a nivel central mediante la Administración Nacional de Educación Pública (ANEP)²- un ente autónomo y con personería jurídica, independiente del Ministerio de Educación y Cultura-. ANEP es el encargado de la regulación de la educación pública (no universitaria) y se responsabiliza por la planificación, gestión y administración del sistema educativo público en todo el país. Además de tener a su cargo la administración de la educación estatal, se encarga del control de la educación privada estableciendo los lineamientos generales para su supervisión y fiscalización ${ }^{3}$.

En el caso uruguayo, aunque con algunas particularidades que, como se verá, lo diferencian de la situación de Argentina, también se corrobora un aumento de la matrícula gestionada por el sector privado durante los últimos años como puede observarse en el Gráfico № 3 .

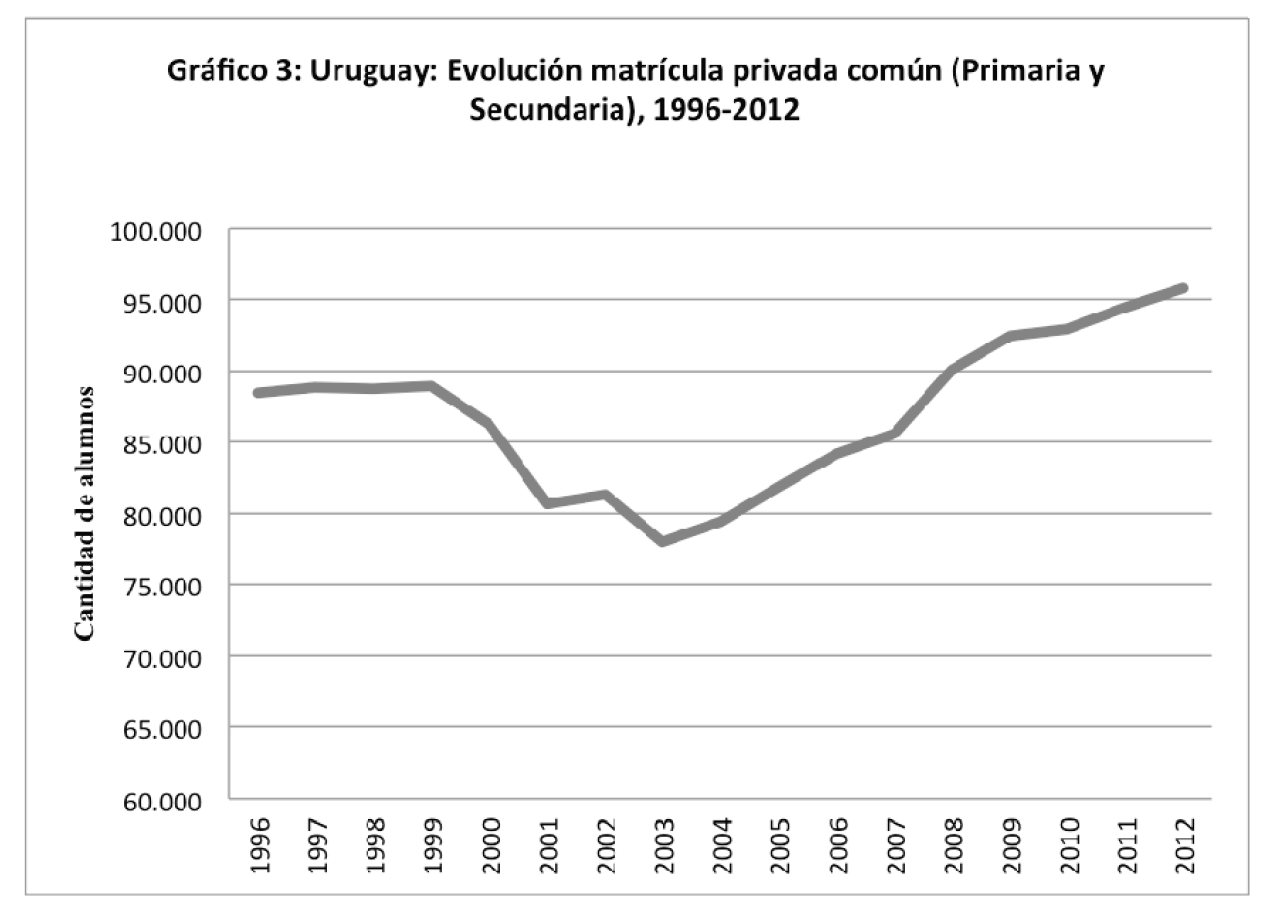

Fuente: Elaboración Propia en base a Uruguay, ANEP, Observatorio de la Educación; División de Investigación, Evaluación y Estadística de CODICEN.

En el gráfico $\mathrm{N}^{\circ} 3$ puede verse que el crecimiento no es sostenido para todo el período en análisis sino que, durante los primeros años (1996-2003), la matrícula privada en primaria y secundaria o bien permanecía estable (1996-1999) o bien caía pronunciadamente (2002-2003), posiblemente por la crisis económica. Para el año 2003 alcanza el valor absoluto mínimo de la serie (con 77.983 alumnos, alrededor de un $14 \%$ menos que en el inicio). Desde entonces, el aumento de alumnos en establecimientos privados es constante: la escuela privada absorbe en el conjunto de los siguientes 9 años un total de 17.832 nuevos alumnos, llegando al 2012 al mayor valor registrado en el total del período recuperando con creces las cifras de 1996. Asimismo, es dable señalar que la matrícula gestionada desde el lado estatal se comporta en forma opuesta. Hasta el año 2003 iba en aumento y posteriormente la baja es pronunciada: entre el 2003 y el 2012, la escuela pública uruguaya pierde más de 59.000 alumnos.

Al considerar el peso que representa la matrícula privada sobre el total de matrícula del sistema educativo, las tendencias son similares (Gráfico № 4). 


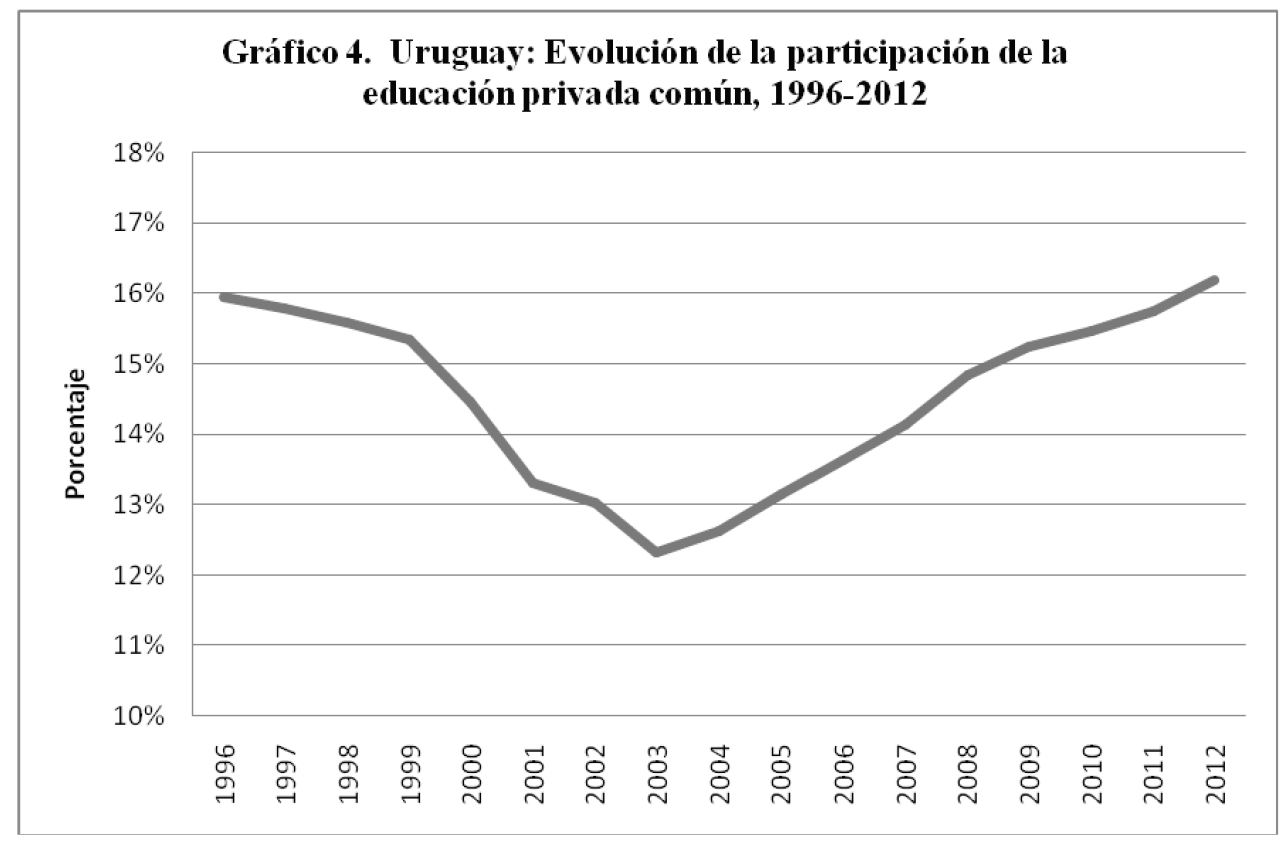

Fuente: Elaboración Propia en base a Uruguay, ANEP, Observatorio de la Educación; División de Investigación, Evaluación y Estadística de CODICEN.

La participación porcentual hasta el año 2003 es marcadamente descendente- oscilando de un 15,95\% a un mínimo registrado en 2003 de 12,32\%. A partir de ese año la participación de la educación privada comienza en forma sostenida y pronunciada a recuperarse llegando al 2012 con el $16,19 \%$ del total de los alumnos para los niveles aquí considerados.

Para el análisis desagregado según las diferentes regiones, debe considerarse que Uruguay es un país con una superficie total de $176.215 \mathrm{~km}$ y su territorio se divide en 19 departamentos. Si bien el sistema político (y educacional) uruguayo difiere enormemente del argentino en la medida en que está centrado en unidad de régimen, las diferencias políticas y socioeconómicas entre los departamentos son análogas a las de argentinas, aunque lejos de ser tan pronunciadas.

Montevideo es su capital y más allá de representar apenas un $0,3 \%$ de la totalidad de la superficie del país, en ella reside el $40.13 \%$ del total de la población ${ }^{4}$. En segundo lugar se encuentra el departamento de Canelones, el cual alberga un $15.83 \%$ de la población uruguaya. De todo el resto de los 17 departamentos ninguno llega a represar un valor superior al $4 \%$ del total.

En congruencia con estos datos se corrobora que es muy elevado el peso de la matrícula que representa el departamento de Montevideo sobre el total del sistema educativo. Para 1996, por ejemplo, del total de alumnos escolarizados en primaria y secundaria común, un $41.45 \%$ asistía a establecimientos radicados en Montevideo y el aglomerado de los restantes 18 departamentos absorbía el $58,55 \%$ de la matrícula.

Tal como puede observarse en el siguiente cuadro (Cuadro $^{\circ} 2$ ), la privatización de la matrícula para los niveles primario y secundario opera principalmente en el conjunto de aquellos 18 departamentos. 
Cuadro № 2: Uruguay. Crecimiento de la matrícula según departamento y sector de gestión, 1996-2012.

\begin{tabular}{|l|r|r|r|r|}
\hline Departamento & $\begin{array}{l}\text { Crecimiento } \\
\text { Privada }\end{array}$ & $\begin{array}{l}\text { Crecimiento } \\
\text { Estatal }\end{array}$ & \multicolumn{1}{l}{$\begin{array}{l}\text { lrecimiento } \\
\text { Total }\end{array}$} & $\begin{array}{l}\text { Privada vs } \\
\text { Estatal }\end{array}$ \\
\hline Montevideo & $-3,56 \%$ & $-6,28 \%$ & $-5,52 \%$ & $2,72 \%$ \\
\hline Resto del País & $39,37 \%$ & $13,36 \%$ & $15,31 \%$ & $26,01 \%$ \\
\hline Artigas & $-40,26 \%$ & $-2,61 \%$ & $-3,32 \%$ & $-37,66 \%$ \\
\hline Canelones & $46,13 \%$ & $24,62 \%$ & $27,02 \%$ & $21,51 \%$ \\
\hline Cerro Largo & $70,54 \%$ & $14,66 \%$ & $16,69 \%$ & $55,88 \%$ \\
\hline Colonia & $8,73 \%$ & $4,74 \%$ & $4,91 \%$ & $3,99 \%$ \\
\hline Durazno & $46,20 \%$ & $6,39 \%$ & $9,22 \%$ & $39,80 \%$ \\
\hline Flores & $157,87 \%$ & $3,30 \%$ & $11,32 \%$ & $154,58 \%$ \\
\hline Florida & $55,90 \%$ & $1,39 \%$ & $3,11 \%$ & $54,51 \%$ \\
\hline Lavalleja & $23,26 \%$ & $6,61 \%$ & $7,82 \%$ & $16,66 \%$ \\
\hline Maldonado & $98,24 \%$ & $32,63 \%$ & $42,33 \%$ & $65,61 \%$ \\
\hline Paysandú & $22,17 \%$ & $8,31 \%$ & $9,53 \%$ & $13,86 \%$ \\
\hline Río Negro & $7,64 \%$ & $14,74 \%$ & $14,30 \%$ & $-7,10 \%$ \\
\hline Rivera & $49,94 \%$ & $14,45 \%$ & $16,05 \%$ & $35,49 \%$ \\
\hline Rocha & $10,85 \%$ & $8,71 \%$ & $8,82 \%$ & $2,13 \%$ \\
\hline Salto & $-2,11 \%$ & $7,47 \%$ & $6,69 \%$ & $-9,58 \%$ \\
\hline San José & $17,13 \%$ & $20,88 \%$ & $20,66 \%$ & $-3,74 \%$ \\
\hline Soriano & $-31,23 \%$ & $0,54 \%$ & $-1,61 \%$ & $-31,77 \%$ \\
\hline Tacuarembó & $13,24 \%$ & $12,27 \%$ & $12,33 \%$ & $0,97 \%$ \\
\hline Treinta & & & & \\
Tres & $109,20 \%$ & $3,77 \%$ & $6,71 \%$ & $105,43 \%$ \\
\hline Total País & $8,26 \%$ & $6,38 \%$ & $6,68 \%$ & $1,89 \%$ \\
\hline
\end{tabular}

Al comparar las variaciones en la matrícula privada y pública entre los años 1996-2012- desagregando los valores del conjunto de los departamentos de los de la capital- se observa que el crecimiento significativo se da fundamentalmente en el resto de país, donde la matrícula privada aumenta casi un $40 \%$ superando ampliamente al crecimiento total así como también al del sector público que, si bien también aumenta, lo hace en una considerable menor medida $(13,36 \%)$.

Es llamativa la situación de Montevideo, donde la matrícula total disminuye, cayendo los valores desde ambos sectores, si bien siendo la pérdida de menor proporción para la escuela privada. Aunque no se poseen estudios que expliquen la situación deberá considerarse seriamente el paralelismo de la situación de Montevideo y de Buenos Aires: incremento de la matrícula privada de vieja data, virtual techo o punto de equilibro para el crecimiento y una composición demográfica que hace que, por motivos vegetativos, haya menos demanda de educación escolar.

Pero el Cuadro № 2 también muestra mayores variaciones entre departamentos que entre provincias argentinas, donde sólo en Tucumán se vislumbraba el predominio de la educación pública. Para el caso uruguayo hay varios departamentos en los que la educación pública crece mucho más que la privada (Artigas, Río Negro, Salto, San José y Soriano) y apenas dos que tienen crecimientos significativos (Maldonado y Flores) mientras que la mayoría de los departamentos en los que ha crecido la educación privada no se ha superado el $60 \%$ contra la educación pública, valores bien más moderados que sus equivalentes argentinos.

Considerando la totalidad del período 1996-2012 se concluye en un crecimiento de mayores proporciones para la educación privada, incluso de mayores proporciones que el crecimiento total. 
De todas maneras, como se ha demostrado, la tendencia al aumento de la matrícula privada a un ritmo mayor que la matrícula estatal parece consolidarse, para el caso uruguayo, especialmente con posterioridad al año 2004.

\section{FINANCIAMIENTO ESTATAL A LA EDUCACIÓN PRIVADA}

\section{a) Argentina: una política de Estado}

Desde hace más de 60 años existe en la Argentina un sistema de apoyo financiero estatal a las escuelas privadas usualmente denominado como "aportes" o "subsidios". La denominación no es legalmente neutral y tuvo su momento de conflictividad: la palabra "aporte" supone que el Estado brinda ayuda financiera como parte de su obligación constitucional en pos de garantizar opciones educacionales a las familias (religiosas, étnicas, culturales, lingüísticas, etc.). "Subsidio", al contrario, refiere a una decisión política discrecional de cada gobierno de transferir recursos a la iniciativa privada.

De la anterior discusión financiera surge que toda educación escolar oficialmente reconocida en la Argentina es pública. La denominación legal del sector privado es "Educación pública de gestión privada" como contrapuesta a la "Educación pública de gestión estatal" tal como lo determinan tanto la Ley Federal de Educación de 1993 como su sustituta, la Ley de Educación Nacional de 2006. Sin embargo, y hechas estas aclaraciones, en el presente estudio -dirigido a una vasta audiencia internacional- hemos optado por hacer abstracción de la terminología consagrada por el debate legal doméstico, por lo que utilizaremos los conceptos "subsidios" y "transferencias" de acuerdo a la jerga usual de la teoría de las finanzas públicas. Y seguiremos denominando a sendos sectores de la oferta escolar como "educación pública" y "educación privada", utilizando la nomenclatura académica tradicional.

Volviendo al sistema argentino de subsidios estatales a la educación privada, este se originó en 1947 con el objetivo de garantizar la escolarización de los alumnos en zonas donde no existieran escuelas estatales u ofrecer ayuda financiera a escuelas privadas a las que asistiera la población de menores ingresos (Morduchowicz, 1999: 44; Rivas y Mezzadra, 2010: 7). El subsidio consiste en el financiamiento estatal a parte del gasto en personal relativo a los docentes que enseñan materias curriculares "oficiales": en el caso de que una escuela privada lo reciba, el subsidio no cubre la inversión en infraestructura, el gasto en personal no docente, el gasto en personal docente extra programático, bienes y servicios no personales, etc.

Este punto marcó la sistematización de una política que posteriormente, y a través de sucesivas normas (de 1964, de 1991), fue adquiriendo mayor definición en cuanto a la proporción de la carga total en salarios docentes a ser financiada por el estado. Esta proporción oscila entre el $40 \%$ y el $80 \%$, aunque también se prevé la posibilidad de percibir un $100 \%$ de los salarios docentes para el caso de las escuelas que no cobran aranceles.

A partir de la propia normativa se sabe que la base del cálculo de la asignación a recibir por cada escuela privada ha sido siempre el gasto en salarios docentes de un establecimiento, y si bien ella establece ciertos criterios para definir la asignación y sus proporciones (nivel socioeconómico de la población atendida, proximidad y disponibilidad de una oferta estatal similar, etc.), estos no resultan exhaustivos y los pocos estudios existentes sobre la cuestión muestran que la decisión respecto de la decisión política de subsidiar o no a una escuela y la determinación final de su monto recae en la voluntad de las autoridades de los Ministerios de Educación de cada provincia (Morduchowicz, 1999: 12; Narodowski, 2002: 183, Rivas, y Mezzadra 2010: 57).

En 2010, el 65\% de los establecimientos educativos privados de la Argentina percibía apoyo financiero estatal en alguna proporción (del $40 \%$ a la totalidad de los salarios docentes). El estudio de Rivas y Mezzadra (2010: 57) acerca del subsidio a escuelas privadas en la Argentina hace foco en la Provincia de Buenos Aires, el principal distrito del país, donde el porcentaje de establecimientos con apoyo financiero estatal es aún mayor que la media nacional, llegando al $73 \%$. El estudio revela que, para la provincia de Buenos Aires, existe cierta progresividad entre la proporción de subsidios 
asignados y el nivel de ingresos de las poblaciones atendidas. Sin embargo, también se registran inconsistencias significativas. Así, "el $17 \%$ de las escuelas del tercio más pobre recibe menos del $50 \%$ de subvención estatal. A su vez, el $16 \%$ de las escuelas del tercio más alto recibe más del $75 \%$ de aportes estatales. (Mezzadra y Rivas, 2010: 58). Otro estudio, utilizando un instrumental estadístico riguroso, ha concluido el carácter progresivo y pro-pobre, para el caso de la misma provincia, de estas transferencias (Guadarucci, Puig y Salinardi, 2012: 25). Lamentablemente, no se poseen datos consistentes para otras provincias.

Como hemos advertido en otros estudios (Narodowski 2002: 182, 2002a: 129), la particularidad del caso argentino radica en que, a diferencia de otros sistemas educativos que han atravesado fuertes procesos de privatización, no existen subsidios a la demanda por lo que no es posible concluir seriamente que el financiamiento estatal al sector privado genere mecanismos de competencia entre el sector estatal y el privado o aún dentro del sector privado. Más aún, el carácter patrimonialista y burocrático de este financiamiento a la oferta escolar parece más bien estar condenado a desincentivar la competencia, ya que el financiamiento de buena parte de ellas no depende de la demanda sino que está garantizada por el perenne apoyo estatal. En resumen, como ya hemos concluido en otros estudios (Narodowski y Nores, 2003; 5 Narodowski, 2008: 12 Narodowski y Moschetti, 2015: 9), merced al tipo de intervención estatal sobre la educación privada, el sistema educativo de la Argentina es un caso claro de privatización sin mercado o "school choice without vouchers", para denominar rigurosamente el concepto usual en la literatura académica internacional.

El subsidio estatal a la educación privada permite, en los hechos, reducir el precio de la cuota escolar y así habilitar el acceso a un determinado establecimiento educacional privado a aquellos sectores sociales que pretenden declinar la vacante gratuita en la educación pública y no estarían en condiciones de financiar esta decisión de no mediar este instrumento.

Por todo lo que se ha aquí explicado es dable de inferir que el subsidio estatal a las escuelas privadas se trata de una verdadera política de Estado, consistente en el tiempo, impermeable al paso de los diferentes gobiernos y ciertamente equivalente -con muy pocas diferencias- entre las jurisdicciones federales de la educación argentina.

En un artículo reciente (Narodowski y Moschetti, 2015: 11) se ha podido concluir, en base a sólida evidencia estadística, que al ser los subsidios a la educación privada el efecto de un conjunto de decisiones políticas y administrativas del Estado tomadas en el largo plazo, su análisis permite comprender cómo esta acción financiera gubernamental acompaña y convalida las decisiones tomadas por las familias en cuanto a enviar a los hijos a una escuela privada. ${ }^{5}$

En ese trabajo se advierte que las transferencias financieras al sector privado constituyen una tendencia siempre creciente en la Argentina, a excepción de los años de la profunda crisis fiscal y social que el país viviera en 2001 y 2002. Sin embargo, es notorio como apenas tres años después de la crisis (en 2005) se retoma el crecimiento de los subsidios y ya en 2006 los valores son mayores, en términos reales, a los inmediatamente previos a la crisis.

Si se desagrega por provincias el incremento del financiamiento a la educación privada para el período 1994-2010, habremos de observar que el incremento de los subsidios para el total del país fue del $199 \%$ en términos reales. Algunas provincias llegan a aumentos de $275 \%$ o $652 \%$ (Formosa, Catamarca) muchas de ellas son las mismas provincias que más han aumentado su matrícula, como ya se había destacado en el Cuadro №1.

5. Además de consolidación del subsidio estatal a la educación de gestión privada se identifican un conjunto de decisiones políticas y administrativas que contribuyeron al crecimiento de las educación privada y que incluso ampliaron su margen de maniobra por sobre el de las escuelas pública. Entre otras, la aceptación de títulos habilitantes o supletorios para el ejercicio particular de la enseñanza, la estabilidad del personal docente en los institutos particulares, y la equiparación de los certificados otorgados a los alumnos por parte de las escuelas privadas a mediados del siglo XX constituyen elementos claves en el crecimiento y consolidación de los servicios educativos de gestión privada (Morduchowicsz, 1999; Nardodowski, Nores y Andrada, 2002; Narodowski, Vinacur y Alegre, 2014). De todas maneras, las causas del crecimiento de la matrícula de la educación privada de la escuela obligatoria, en un escenario en donde el Estado ofrece escuela pública gratuita obedece a razones complejas, algunas de las cuales han sido estudiadas para el caso argentino (Lopez, 2002, Scialabba, 2006; Vinacur y Scialabba, 2008). 
Cuadro $N^{\circ}$ 3: Argentina-Crecimiento de las transferencias al sector privado 1994-2010 Jurisdicciones ordenadas por PBG 2005 (En millones de pesos de 1993)

\begin{tabular}{|l|l|}
\hline Jurisdicción & Crecimiento \\
\hline Buenos Aires* & $316 \%$ \\
\hline C.A.B.A. & $127 \%$ \\
\hline Santa Fe & $171 \%$ \\
\hline Córdoba & $148 \%$ \\
\hline Neuquén & $107 \%$ \\
\hline Mendoza & $81 \%$ \\
\hline Entre Ríos & $209 \%$ \\
\hline Misiones & $278 \%$ \\
\hline Santiago del Estero & $759 \%$ \\
\hline Corrientes & $1062 \%$ \\
\hline Río Negro & $442 \%$ \\
\hline Chaco & $343 \%$ \\
\hline Tucumán & $140 \%$ \\
\hline Chubut & $121 \%$ \\
\hline Santa Cruz & $323 \%$ \\
\hline Salta & $227 \%$ \\
\hline San Luis & $201 \%$ \\
\hline San Juan & $143 \%$ \\
\hline Jujuy & $210 \%$ \\
\hline La Pampa & $163 \%$ \\
\hline Tierra del Fuego & $519 \%$ \\
\hline Catamarca & $653 \%$ \\
\hline La Rioja & $153 \%$ \\
\hline Formosa & $275 \%$ \\
\hline Total País* & $199 \%$ \\
\hline & \\
\hline
\end{tabular}

Fuente: Narodowski y Moschetti, 2015 *Período 1994-2009 (último dato oficial publicado)

Pero el dato más relevante del estudio citado (Narodowski y Moschetti, 2015: 12) resulta al comprender que más allá de algunas excepciones, la relación entre crecimiento de la matrícula y financiamiento estatal a la oferta escolar aparece como una correlación estadística muy estrecha. En el siguiente gráfico se observa que la mayoría de las provincias se encuentran posicionadas en una relación consistente entre una variable y otra.

\section{Gráfico № 5: Jurisdicciones según crecimiento de la matrícula} y de las transferencias al sector privado, 1994-2010

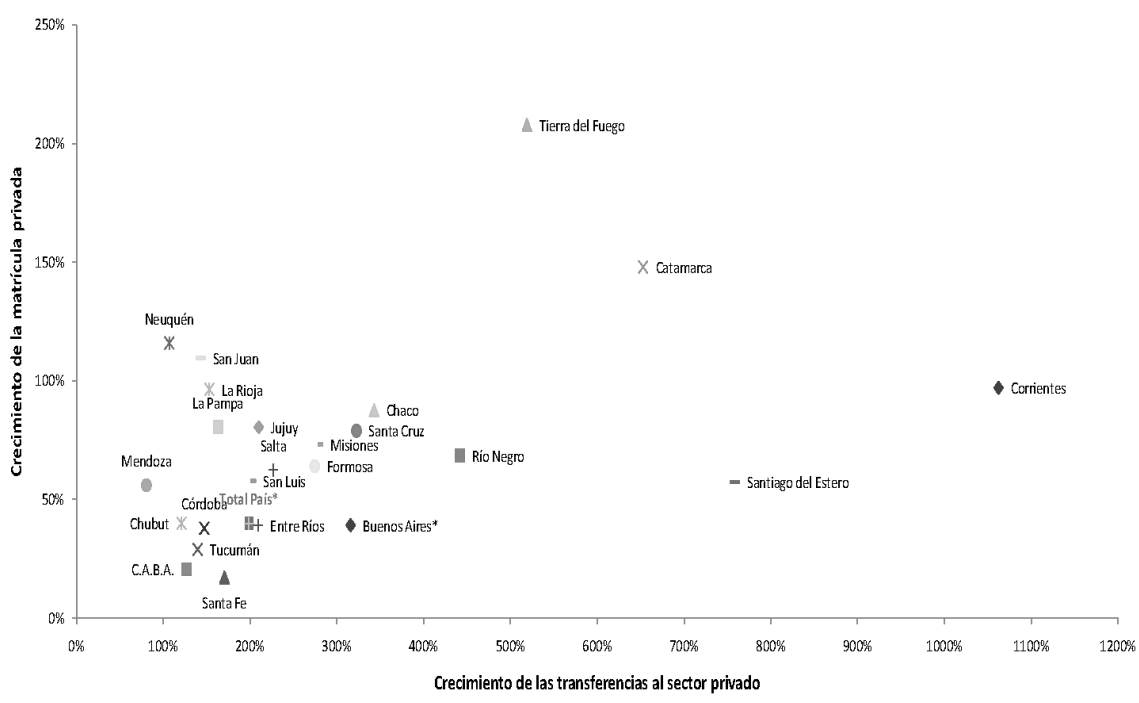

Fuente: Narodowski y Moschetti, 2015 
El gráfico $\mathrm{N}^{\circ} 5$ muestra con claridad que 20 de los 24 distritos tienen un comportamiento consistente entre el crecimiento de la matrícula y el incremento del financiamiento estatal a pesar de las enormes diferencias sociales, culturales y económicas dadas entre provincias. Solamente 4 provincias argentinas se alejan del común denominador del resto de las jurisdicciones. Se trata de provincias pequeñas, de pocos habitantes (en conjunto no llegan al $6 \%$ de la población argentina) y que en todos los casos han tenido un incremento del financiamiento estatal muy superior a la media. En los casos de Tierra del Fuego y Catamarca, el crecimiento del financiamiento ha sido acompañado por un fuerte crecimiento de la matrícula privada pero no así en Santiago del Estero y Corrientes donde se registra cierta desproporción entre variables.

\section{b) Uruguay y su tradición de no financiamiento estatal al sector privado}

El caso uruguayo, al contrario del recién descripto, muestra un escenario de financiamiento estatal a la educación privada completamente diferente. Los subsidios estatales a la educación privada no existen bajo ningún punto de vista a no ser la exención (exoneración, en la jerga legal uruguaya) impositiva (nacional y municipal) a las escuelas privadas, establecida en el artículo 69 de su Constitución Nacional, incluyéndose en esta exoneración a los aportes patronales (que sí pagan las instituciones públicas).

Es verdad que técnicamente se trata de un subsidio indirecto que, en el margen, permitiría, al menos en la teoría, reducir los costos tributarios de la entidad educacional. Sin embargo, al tener el sistema de escuelas públicas prácticamente la misma exoneración (y siendo gratuitas) este subsidio indirecto a los costos difícilmente permita bajar los precios significativamente, como ocurre en la Argentina gracias a los subsidios directos que pueden llevar el precio a cero, cosa que sólo ocurre en el Uruguay en el caso de las escuelas privadas financiadas íntegramente por donantes y benefactores (quienes a su vez pueden tener exenciones tributarias).

Además, en la Argentina, la mayoría de las escuelas privadas también están exentas de impuestos en forma inmediata si son instituciones sin fines de lucro y por medio de trámites especiales si no lo son. Y también, obviamente, pueden recibir donaciones que minimicen el pago de la cuota familiar.

Esto significa que, salvo el caso de las escuelas uruguayas privadas de precio cero merced a donaciones privadas -como los muy reconocidos liceos Impulso y Jubilar-, el esfuerzo financiero familiar para enviar a los hijos a la escuela privada en el Uruguay es solamente comparable al de las familias argentinas que envían a sus hijos a escuelas privadas sin apoyo financiero estatal, las cuales son, a la sazón, las menos y las más caras. En conclusión, en términos relativos es más oneroso para una familia uruguaya mandar a sus hijos a escuelas no públicas que lo que le resulta a una familia argentina, quienes podrían elegir una escuela con precios subsidiados. Este ha de ser un elemento que no podrá soslayarse al momento de procurar comprender los diez puntos de diferencia porcentual de participación de la matrícula privada primaria y secundaria en el Uruguay $(16,3 \%)$ y en la Argentina $(26,9 \%)$.

Una nota final respecto de la cuestión financiera. Obsérvese cuidadosamente que en ninguno de los dos países aquí analizados existe en la práctica de la política educativa nada parecido a lo que en la bibliografía antes citada aparece como el desiderátum neoliberal respecto al financiamiento educacional: es evidente que ni en la Argentina ni en el Uruguay existen subsidios financieros estatales a la demanda (como en el caso chileno) ni tampoco exenciones impositivas a los padres que envían a sus hijos a escuela privada.

No solamente que ninguno de estos dos sistemas educativos ni se aproxima a un cuasi mercado educacional sino que tampoco hubo "experimentos" de aplicación de vouchers durante el período aquí estudiado, ni mucho menos antes. En la Argentina hay subsidios a la oferta desde varias décadas anteriores al auge del neoliberalismo y, de hecho, nada más lejano a un incentivo a la competencia y pro mercado que este tipo de transferencias, ineficientes desde el punto de vista de la competencia en un mercado perfecto. En el Uruguay directamente no hay transferencias estatales $y$, apenas, un subsidio indirecto que mitiga en el costo tributario. 
A modo de cierre de esta sección, y anticipando futuros abordajes, es posible al menos conjeturar que el sistema educativo uruguayo y el argentino conforman sendos cuasi monopolios estatales (Narodowski, 2008: 11 y 2010: 32): un híbrido conformado por el viejo sector monopólico estatal que ofrece educación gratuita al que se le articula un sector privado (o de "salida") crecientemente desregulado y que, aún con apoyo financiero estatal directo o indirecto, su tolerancia se corresponde con el crecimiento total de la matrícula y la costo efectividad del esfuerzo fiscal.

\section{LA PRIVATIZACIÓN DE LA EDUCACIÓN DESPUÉS DEL “NEOLIBERALISMO” Y DEL "ANTINEOLIBERALISMO"}

La pregunta central frente al panorama hasta aquí reseñado es si se estaría mostrando un predominio de las políticas educativas neoliberales, para el período estudiado, a partir del momento en que el crecimiento de la matrícula privada se torna en ambos países muy significativo: 2003-2005 ¿Serían estas políticas neoliberales la causa central del aumento sostenido de la matrícula de educación privada que no es acompañado por el crecimiento de la educación pública, el que parece quedar siempre a la retaguardia de aquél?

Durante los años noventa del siglo XX, efectivamente la política económica de la mayoría de los países latinoamericanos estuvo fuertemente influida por políticas que fomentaban la apertura indiscriminada de la economía, la privatización de los servicios públicos y la aplicación de mecanismos pro mercado a las más diversas áreas de la vida económica y social.

En el caso argentino, especialmente durante el gobierno justicialista de 1989-1999, encabezado por el Presidente Carlos Menem, pasaron a manos privadas las empresas antes estatales proveedoras de agua potable, gas, electricidad, telefonía, rutas, correos, puertos y el transporte aéreo y ferroviario. La línea marítima nacional así como muchos ramales ferroviarios fueron definitivamente clausurados argumentando ineficiencia y sus empleados despedidos.

Además, todas las empresas productivas dependientes del Estado o bien pasaron a manos privadas (como la extracción y comercialización de petróleo) o fueron directamente disueltas (como algunas minas de carbón). En lo que respecta a la relación capital trabajo, los salarios quedaron virtualmente congelados con muy altos niveles de desocupación y aumentos sólo por productividad. Finalmente, con la independencia del Banco Central, el Estado perdió en control sobre la moneda, el crédito y el tipo de cambio en favor del libre mercado. Durante los años noventa Argentina vivió una fuerte apertura de su economía y el concomitante ingreso de bienes y capitales (Kiguel 2002: 1).

Aún volviendo a reconocer el carácter polisémico del concepto "neoliberalismo" (Narodowski y Nores, 2003: 2) y de registrar que el mismo acepta, incluso, varias definiciones no congruentes entre sí, es difícil de discutir el sesgo neoliberal de la política económica argentina en los años noventa. Para muchos estudiosos del tema educacional, este perfil neoliberal es el que se traduce en el campo de los sistemas educativos perfilando un incremento de la oferta de educación privada y así varios autores caracterizaron a la Ley Federal de Educación, sancionada en 1993, como el elemento regulatorio clave de la entrada del neoliberalismo a las escuelas argentinas (Puiggrós, 1997: 82). Incluso hay evidencia de que los operativos nacionales de evaluación de la educación implementados a partir de 1991 resultan de una evidente condición impuesta por el World Bank para otorgar créditos al país para el sector educativo (Narodowski; Nores y Andrada, 2002: 73).

Como contraposición a la década del gobierno neoliberal del presidente peronista Carlos Menem, aparece en el debate político argentino el gobierno antineoliberal de los también peronistas Néstor Kirchner (2003-2007) y Cristina Fernández de Kirchner (2007-2011 y 2011-2015). Esta serie de mandatos se inicia con posterioridad al breve gobierno de De la Rua (1999-2001) que terminó en la mayor crisis económica y política de la historia argentina, la mundialmente famosa sucesión de varios presidentes en una misma semana de diciembre de 2001 hasta la asunción de Eduardo Duhalde (2001-2003) que llamó a elecciones en el contexto de la normalización política del país (Carranza 2005: 67). 
La política económica a partir de los gobiernos de Néstor y Cristina Kirchner desde 2003 (conocida en la Argentina como "la era K") fue presentada por el nuevo gobierno como diametralmente opuesta al neoliberalismo del gobierno de Carlos Menem. A partir de un proceso sostenido, el Estado comienza a tener más intervención en la economía. Así, las empresas proveedoras de agua potable son re estatizadas al igual que algunas rutas, el correo argentino, y algunos puertos.

El transporte aéreo vuelve a tener a una aerolínea de bandera de capital estatal gerenciada por el Estado y se reabre a cargo de éste la línea marítima nacional. Algunos de los ramales ferroviarios clausurados en la década de los noventa son reinaugurados. El gobierno retoma el control de algunas de las empresas productivas privatizadas (especialmente el petróleo) y llega a expulsar a compañías privadas de su actividad en diferentes pozos. Respecto del Banco Central, el nuevo gobierno reivindica su necesidad de alineación a los intereses de la economía nacional y se modifican regulaciones para que el Estado controle la moneda y especialmente el tipo de cambio.

A partir de 2003, el Estado argentino controla crecientemente las importaciones y cobra impuestos a las exportaciones agropecuarias. Con el nuevo empuje de la economía, desciende el número de desempleados, se descongelan los salarios y se habilitan nuevamente las negociaciones laborales. Respecto de los organismos de crédito internacionales, en 2005 se produce una medida de "desendeudamiento" con el pago del total de la deuda mantenida con el Fondo Monetario Internacional con el objetivo explícito de que las medidas políticas no sean afectadas en su soberanía por los organismos internacionales de crédito. Si bien esta política económica pretendidamente antineoliberal no vuelve el status quo a la situación anterior a 1989, es evidente que el Estado retoma el control de muchos sectores estratégicos de la economía (Grugel y Riggirozzi, 2007: 92).

Para el caso uruguayo las cosas fueron bien diferentes dado que los intentos de reforma pro mercado de inicios de los años noventas fueron si no vencidos, al menos mitigados políticamente. Incluso algunas de estas propuestas fueron derrotadas en consultas populares electorales convocadas a efectos de convalidarlas. Incluso, la reforma constitucional de 2004 puso límites precisos a la expansión del sector privado dentro del escenario estatal tradicional.

Sin embargo, retomando autores ubicados clara y explícitamente en un enfoque "antineoliberal" es posible caracterizar al escenario uruguayo como "neoliberal" a pesar de las enormes diferencias con la Argentina. Diferencias no solamente en el ímpetu o el ethos pro mercado de su clase política sino incluso en la estructura y organización de las reformas. De cualquier manera, y ya aclarado el concepto polisémico de "neoliberalismo", valen un par de párrafos para situar la experiencia política oriental bajo la luz de dicho concepto a fin de observar mejor el comportamiento de las variables educacionales aquí en estudio.

Daniel Chavez explica en un artículo en el que se plantean las alternativas que los gobiernos "progresistas" deben construir respecto de su pasado neoliberal (que Uruguay mantuvo desde 1985 con el advenimiento de la democracia hasta 2004 con la victoria electoral del Frente Amplio) que los dos partidos tradicionales del Uruguay -el blanco y el colorado- "llevaron adelante gobiernos de coalición que impulsaron diversas políticas privatizadoras" (2007: 67) y si estas medidas, continúa el mismo autor, no tuvieron un auge similar al del resto de los países de América Latina esto se debió a la oposición de sindicatos, movimientos sociales y partidos políticos progresistas y de izquierda (Ibídem.)

El autor enumera entre dichas medidas la privatización (y desregulación) del mercado eléctrico, la privatización del sector de agua y saneamiento, (lo que hubo generado un significativo aumento de tarifas a los sectores de menores recursos), la extranjerización de empresas estatales o de capital uruguayo y la política económica y de servicios públicos confeccionadas de acuerdo a las directivas del Banco Mundial, al igual que la política monetaria y fiscal cercana a las líneas directrices del Fondo Monetario Internacional (Chavez, 2007: 70).

Según algunos autores (Riella y Andrioli, 2004:191) estos gobiernos de los partidos democráticos no hicieron más que profundizar las medidas neoliberales que ya venían desarrollándose "desde la dictadura militar", amparándose en fracciones de clase (como la burguesía ganadera) que daban sustento simbólico a las reformas emprendidas. La apertura de la economía y los llamados "acuerdos 
de libre comercio con los estados Unidos, promovidos en el ciclo "neoliberal" y abortados en el ciclo político posterior cierran la imagen del andarivel neoliberal que el Uruguay recorriera en años recientes.

En el plano de las políticas educativas, para el caso argentino, a partir del 2003 el gobierno se posiciona con un discurso político fuertemente contrario a la política educativa de gobierno de Menem y particularmente a la Ley Federal de Educación, sancionada en los noventas.. Es así que a requerimiento del gobierno, el Congreso Nacional en los inicios del 2006 deroga la denostada por neoliberal Ley Federal de Educación y sanciona una nueva Ley. ${ }^{6}$ Además de ésta, el Gobierno surgido en 2003 consiguió la sanción de todas las leyes que le hubo solicitado al Parlamento: Ley de Financiamiento Educativo, Ley para garantizar 180 días de clase, Ley de Educación Sexual, Ley de Paritarias Docentes, Ley de Educación Técnica, entre otras (Feldfeber y Gluz, 2011: 345).

Para el caso uruguayo, las cuestiones vinculadas a la educación vuelven a ser diferentes. La caracterización de "neoliberal" de las políticas educativas de los 90 estuvieron en debate dado que si bien los sindicatos docentes así las caracterizaban (al igual que en la Argentina), otros sectores, incluso "progresistas" veían en ella un hito más en la tradición estatista uruguaya. Marrero \& Cafferatta (2008: 197) arguyen que "No hubo privatización de la enseñanza, y la educación privada no logró, en este período, ninguno de los beneficios que esperaba", aunque "la reforma educativa [de los 90s] fue continuadora de las políticas neoliberales instauradas en el país durante la dictadura militar" (Dominguez \& Gatti, 2011: 361).

En los años dos mil, el gobierno del Frente Amplio convoca a un gran debate nacional de la educación que, posicionándose con claridad en contra del ciclo neoliberal, congregó a docentes y funcionarios de la enseñanza que reclamaron "un nuevo sistema nacional de educación, público, estatal, autónomo y cogobernado" (Marrero \& Cafferatta, 2008: 199)

En este contexto, si las políticas neoliberales eran la causa de la privatización de la educación -tal como aparece en los enunciados teóricos ya explicados- sería esperable entonces un cambio de

$:: 66::$ tendencia en cuanto a la relación entre la matrícula de la educación pública y de la educación privada en la Argentina y en el Uruguay a partir del momento en que agrupaciones o frentes partidarios con posicionamientos explícitamente antineoliberales se hacen cargo del gobierno en ambos países. Más todavía, en el análisis de las "nuevas leyes" de educación sancionadas durante los gobiernos "progresistas" de América Latina, Safocarda y Vassiliadis (2011: 262) observan que "en los casos de Argentina y Uruguay, el Estado asume un rol principal en la responsabilidad por garantizar una educación integral, permanente y de calidad para todos los habitantes a través del financiamiento y de la definición y el desarrollo de la política educativa". Con semejantes antecedentes, la continuidad lógica de los argumentos teóricos indicaría un aumento si no abrupto al menos tendencial en la participación de la educación pública como forma de expresar la principalidad del Estado consagrada en las nuevas leyes educacionales nacionales del escenario antineoliberal. Sin embargo, los datos mostrados en las secciones anteriores del presente estudio ya anticipaban un cierto pesimismo de que esto ocurriera. Así, la evidencia que se expone a continuación demuestra una clara tendencia en contrario.

Para el caso de las provincias argentinas se observa que es en el período de gobiernos de Néstor y Cristina Kirchner cuando en todas ellas (salvo, de nuevo, en Tucumán) se incrementa la matrícula privada, en algunos casos en forma francamente llamativa, como demuestra el Cuadro № 4. 


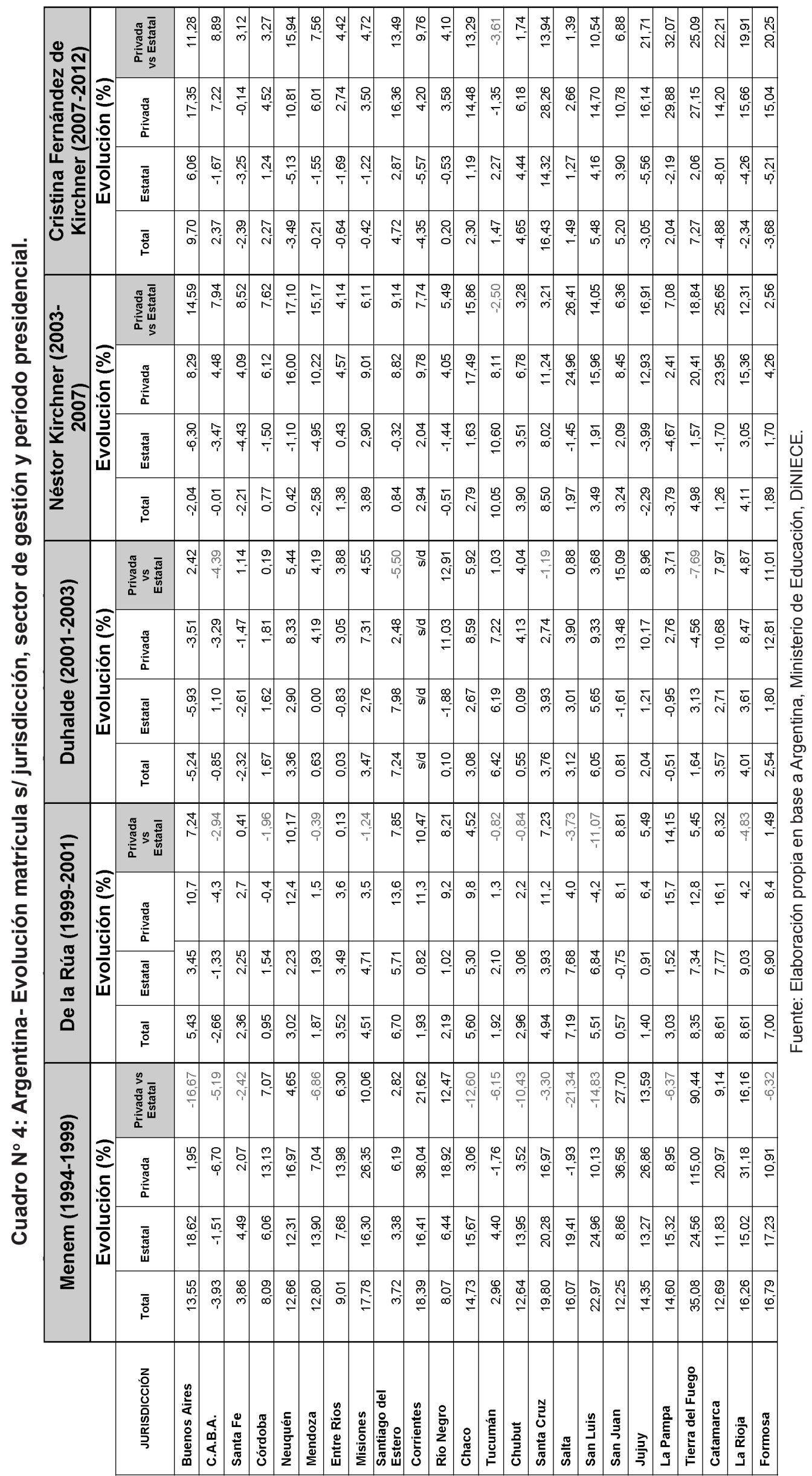




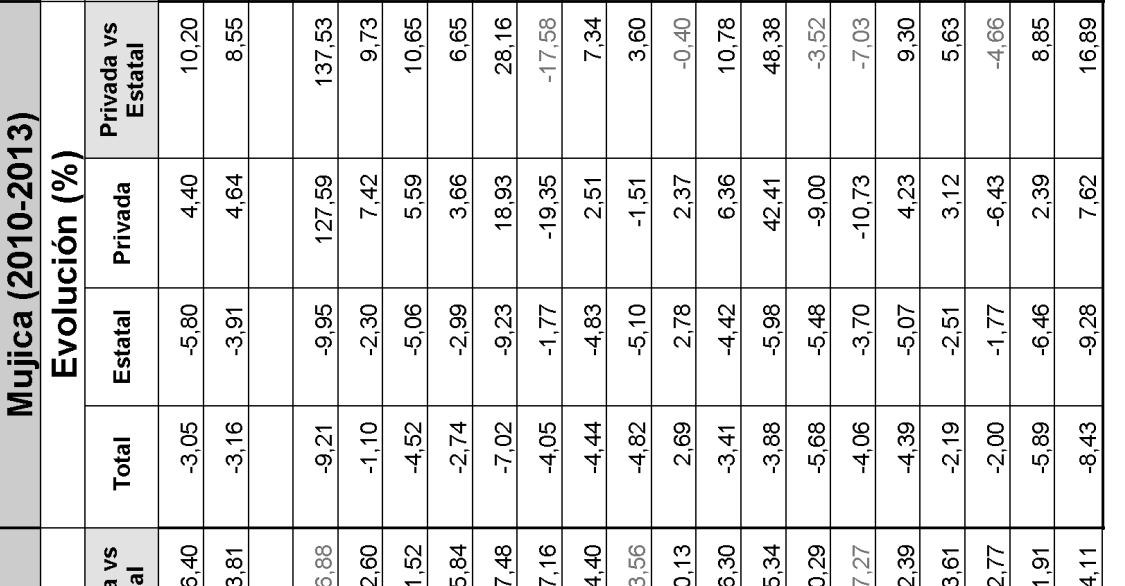

으

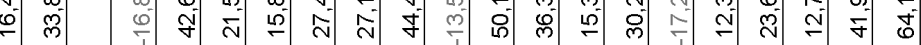

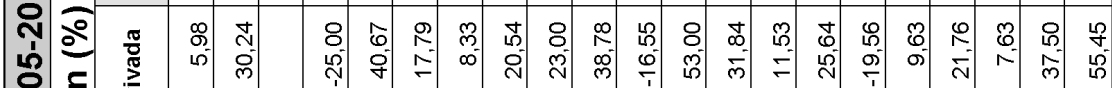

过

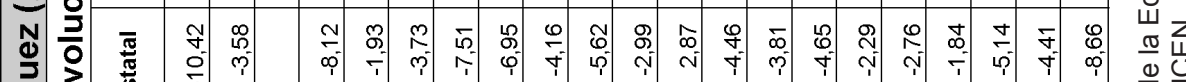

式山岕

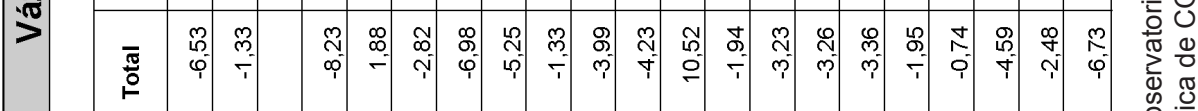

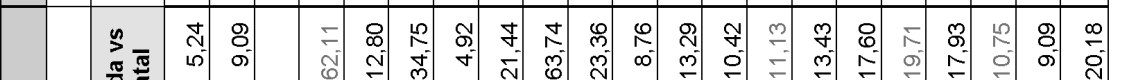
Оำ 
Para una visión menos analítica, el cuadro siguiente resume la evolución de la matrícula para el total de cada país por período presidencial (Cuadro № 6)

\section{Cuadro № 6: Argentina y Uruguay- Evolución matrícula total según sector de gestión y período presidencial.}

\begin{tabular}{|c|c|c|c|c|c|c|c|c|c|}
\hline & \multicolumn{5}{|c|}{ ARGENTINA } & \multicolumn{4}{|c|}{ URUGUAY } \\
\hline & $\begin{array}{c}\text { Menem } \\
(1994- \\
1999) \\
\end{array}$ & $\begin{array}{c}\text { De la } \\
\text { Rúa } \\
(1999- \\
2001) \\
\end{array}$ & $\begin{array}{c}\text { Duhalde } \\
(2001- \\
2003) \\
\end{array}$ & $\begin{array}{c}\text { Kirchner } \\
(2003-2007)\end{array}$ & $\begin{array}{c}\text { Cristina F. de } \\
\text { Kirchner } \\
(2007-2012)\end{array}$ & $\begin{array}{l}\text { Sanguinetti } \\
(1995-2000)\end{array}$ & $\begin{array}{l}\text { Battle } \\
(2000- \\
2005)\end{array}$ & $\begin{array}{c}\text { Vázquez } \\
(2005-2010)\end{array}$ & $\begin{array}{c}\text { Mujica } \\
(2010- \\
2013)\end{array}$ \\
\hline Evol. Total & $10,76 \%$ & $3,74 \%$ & $-1,00 \%$ & $0,09 \%$ & $3,78 \%$ & $13,57 \%$ & $-9,78 \%$ & $-3,31 \%$ & $-3,12 \%$ \\
\hline Evol. Estatal & $12,84 \%$ & $3,14 \%$ & $-1,15 \%$ & $-2,30 \%$ & $1,39 \%$ & $16,67 \%$ & $-10,44 \%$ & $-5,87 \%$ & $-4,51 \%$ \\
\hline Evol. Privado & $4,25 \%$ & $5,8 \%$ & $-0,48 \%$ & $7,90 \%$ & $10,87 \%$ & $-4,24 \%$ & $-5,15 \%$ & $13,57 \%$ & $4,49 \%$ \\
\hline $\begin{array}{c}\text { Privada vs } \\
\text { Estatal }\end{array}$ & $-8,60 \%$ & $2,61 \%$ & $0,67 \%$ & $10,20 \%$ & $9,48 \%$ & $-20,91 \%$ & $5,29 \%$ & $19,43 \%$ & $9,00 \%$ \\
\hline
\end{tabular}

Fuente: Elaboración propia en base a Argentina, DiNIECE y Uruguay, ANEP.

Está claro que el discurso político pro/anti mercado y el posicionamiento a favor/en contra del neoliberalismo y las políticas educativas asumidas, al menos en la proclama, poco se emparentan con una evidencia que marca que en los momentos de emergencia de gobiernos críticos de la privatización de la educación es cuando esta más se hace presente en el comportamiento de la matrícula.

\section{CONCLUSIONES}

La evidencia aquí expuesta resulta consistente con un conjunto de conclusiones respecto de la política educativa llevada adelante entre los diferentes gobiernos (de supuesto signo neoliberal o antineoliberal) en lo relativo al crecimiento de la educación privada para los casos argentino y uruguayo:

En primer lugar, no parece existir evidencia alguna que permita afirmar que el crecimiento de la matrícula de las escuelas privadas en ambos países esté vinculada al posicionamiento político/ ideológico de carácter "neoliberal" de sus respectivos gobiernos. Por el contrario, durante el llamado "período neoliberal" las escuelas públicas todavía aparecían con chances de captar matrícula por sobre las escuelas privadas. Tanto durante la denominada "era K" como durante la sucesión de los gobiernos frenteamplistas, el proceso privatizador parece haberse consolidado muy firmemente: los datos ya expuestos no sugieren un mínimo cambio de tendencia relevante en lo relativo al crecimiento de la matrícula ni a la disímil lógica de financiamiento estatal al sector privado.

Segundo, este proceso privatizador atañe tanto al sistema educativo uruguayo (en lo relativo a los dos niveles aquí estudiados) como a todo el sistema educativo argentino, no existiendo distinciones significativas respecto de provincias y de departamentos. Siendo la Argentina un país de administración educacional federal (en el que las escuelas dependen de cada jurisdicción) y el uruguayo un sistema centrado en unidad de régimen, y teniendo en cuanta las evidentes diferencias sociales, económicas y políticas interprovinciales e interdepartamentales, respectivamente, es visible que el crecimiento de la educación privada en el período "antineoliberal" se da en todas las provincias argentinas y en muchos de los departamentos uruguayos, con las pocas salvedades descriptas antes.

En tercer lugar, las medidas económicas aplicadas en la Argentina que habían sido efectivas en ambos períodos de gobierno, primero para consolidar una economía de mercado y más tarde para devolverle al Estado los controles sobre la economía y las medias económicas equivalentes resistidas en el Uruguay y que dieron lugar a una política pro mercado más moderada, no han tenido un reflejo que se corresponda con las políticas educativas en términos de efectividad. 
La privatización de la educación en la Argentina -y también aunque con menos impacto en el Uruguay- era previa al llamado "período neoliberal" y su tendencia creciente no sólo no sufre modificaciones durante el período antineoliberal sino que, al contrario, se consolida a la suba. Las regulaciones operadas en los dos países durante los años dos mil -con la modificación de la normativa educacional anterior y la aprobación de nuevas numerosas leyes- no solo que no detuvieron el proceso privatizador sino que incluso, a la vista de los resultados obtenidos, terminaron por configurar el escenario adecuado para su consolidación. Más allá de voluntades preexistentes y supuestas intenciones exteriorizadas discursivamente, los datos marcan que es en el período antineoliberal cuando crece con mayor énfasis la educación privada en ambas naciones rioplatenses.

Cuarto, el proceso de la privatización de la educación en la Argentina y en el Uruguay ha mantenido un carácter "exógeno", en el sentido de Ball y Youdell (2008: 74) y es el Estado el que ha promovido su crecimiento en la Argentina y tolerado en el Uruguay. El mecanismo utilizado en el primer caso es el subsidio a la oferta que cuenta con varias décadas de existencia y se mantiene firme en su crecimiento sumado a la equiparación de los certificados otorgados por las escuelas privadas. Para el segundo caso, en el que no existe más que unos pocos subsidios indirectos, al igual que en la Argentina el Estado habilita en el sector privado una autonomía que los sectores estatales no tienen. En este contexto es dable de señalar que, en ambos casos, la política educativa vinculada a la privatización de la educación no ha generado mercados educacionales, ni cultura escolar managerialista ni un ethos generalizado basado en la competencia y/o el lucro. Esta privatización sin mercado más bien parece acercarse a la lógica patrimonialista y burocrática del funcionamiento de un cuasi-monopolio estatal del sistema educativo (Narodowski, 2008: 21).

Finalmente, la persistencia en el tiempo de esta tendencia a la privatización de la matrícula escolar que abarca gobiernos de signo ideológico diferente los que, incluso, pueden llegar a reprocharse recíprocamente decisiones políticas adoptadas en cada turno, difícilmente pueda ser adjudicada al azar de la historia. La impresión global, y las coincidencias entre ambos países, es la de estar en la presencia de un conjunto de consensos básicos en la sociedad y en el Estado por medio de los cuales el respaldo a la matriculación en establecimientos privados es sostenido a través de una

::70:: política de Estado de subsidios y desregulación, a lo que se suma una percepción de fortaleza de la escuela privada y de debilidad de la escuela pública por parte de amplios sectores sociales, tanto clases medias (Scialabba, 2006: 86) como sectores de bajos recursos económicos (Botinelli, 2012: 2, El País, 2012: 1, Gómez Schettinni, 2007: 102) ${ }^{7}$.

Así, queda claro que las explicaciones aquí largamente expuestas, basadas en el auge neoliberal para comprender la privatización de la educación en América Latina, resultan muy insuficientes a la luz de la evidencia expuesta para los casos argentino y uruguayo. Por supuesto, siempre podrá quedar una suerte de consuelo de imaginar que no siempre los gobiernos que se autodenominan "anti neoliberales" efectivamente lo sean y que, por lo tanto, habrá que esperar el advenimiento de un genuino "antineoliberalismo" para revertir la privatización de la educación. Al contrario, la lectura de la evidencia estadística obtenida no supone afirmar que los gobiernos de Néstor y Cristina Kirchner o los del Frente Amplio posean una "intención" manifiestamente "privatizadora". Lo que se trata de confirmar es que ni el discurso político ni los posicionamientos ideológicos de los gobiernos y los efectores de políticas públicas (e incluso las leyes derogadas y vueltas a sancionar) poseen relevancia explicativa y, según se muestra, poco tienen que ver con variables más profundas del comportamiento de la sociedad y el Estado en relación con la elección de escuelas por parte de las familias.

Un análisis más riguroso necesita ponderar variables de complejidad creciente que vayan más allá de posturas ideológicas o de la identificación de ciclos macropolíticos que, se ha demostrado en este estudio, no necesariamente alteran los grandes trazos del devenir de los sistemas educativos: es necesario contribuir a la construcción de modelos teóricos que den cuenta en forma más precisa del interjuego entre un conjunto de variables que de alguna manera permitan explicar estos procesos tan complejos. Para el caso de la Argentina, algunos aportes ya hemos efectuado (Narodowski, 2008: 21 y 2010: 34; Moschetti, 2012: 58). 


\section{ÍNDICE DE FUENTES}

\section{SECUNDARIAS}

\section{Bibliografía}

BALL, S. J. (2009): "Privatising education, privatising education policy, privatising educational research: network governance and the 'competition state"', Journal of Education Policy, Vol. 24, № 1, pp. 83-99

BALL, S. J. and YOUDELL, D. (2008): "Hidden Privatisation in Public Education", Education Review, Vol. 21, No 2 .

BOTINELLI, E. (2012): "Encuesta Nacional Factum", Factum Digital. Revista de Análisis Político, Opinión Pública y Estudios Sociales. Disiponible en_http://www.factum.edu.uy/node/683

CARRANZA, M. (2005): "Poster Child or Victim of Imperialist Globalization? Explaining Argentina's December 2001 Political Crisis and Economic Collapse." Latin American Perspectives 32 (6): 6589.

CENM (Centro de Estudios Nueva Mayoría) (2007): "Desigualdad Provincial: Santiago del Estero Tiene un Ingreso per Cápita 8 Veces Menor al de la Capital Federal." Disponible en http://www. nuevamayoria.com/ES/INVESTIGACIONES/socio_laboral/070802.html

CEPAL (1990): Enseñanza primaria y ciclo básico de educación media en el Uruguay, Montevideo, CEPAL.

CHAVEZ, D. (2007): "Hacer o no hacer: los gobiernos progresistas de Argentina, Brasil y Uruguay frente a las privatizaciones". Nueva Sociedad, 207, 63-79.

DOMÍNGUEZ, L., \& GATTI, E. (2011): "Uruguay: ¿transformación o retorno? (ensayo)". Educação \& Sociedade, 32(115), 357-372.

El País, (28 de noviembre 2012), "Casi la mitad de los uruguayos prefiere la educación privada", Uruguay. Disponible en: http://historico.elpais.com.uy/121128/ultmo-678380/ultimomomento/casi-lamitad-de-los-uruguayos-prefiere-la-educacion-privada/

FELDERFEBER, M. GLUZ, N. (2011): "Las políticas educativas en Argentina. Herencias de los '90. Contradicciones y tendencias de "nuevo signo", Educação \& Sociedade 32 (115), pp. 339-356

FRIEDMAN, M. (2002): Capitalism and Freedom. Chicago: University of Chicago Press.

GIROUX, H. A. (2005): "The Terror of Neoliberalism: Rethinking the Significance of Cultural Politics", College Literature, Vol. 32, №. 1, pp. 1-19.

GÓMEZ SCHETTINI, M. 2007: "La elección de los no elegidos: los sectores de bajos ingresos ante la elección de la escuela en la zona sur de la Ciudad de Buenos Aires." En NARODOWSKI, M. y GÓMEZ SCHETTINI, M. Escuelas y familias. Problemas de diversidad cultural y justicia social. Buenos Aires: Prometeo.

GRUGEL, J. and M. P. RIGGIROZZI (2007): "The Return of the State in Argentina." International Affairs, Vol. 83, № 1, pp. 87-107.

GUARDARUCCI, I.; PUIG, J. Y SALINARDI, L. (2012): "Incidencia del gasto público en educación: nueva evidencia para la Provincia de Buenos Aires en base a la Encuesta Anual De Hogares", CEDLAS, Working Papers, Universidad Nacional de La Plata.

JESSOP, R. (2002): The Future of the Capitalist State. Cambridge: Polity.

KIGUEL, M. (2002). "Structural Reforms in Argentina: Success or Failure?." Comparative Economic Studies Vol. 44 № 2-3, pp. 83-102.

KLEES, S. J. (2008): "A quarter century of neoliberal thinking in education: misleading analyses and failed policies", Globalisation, Societies and Education, Vol. 6, № 4.

LIPMAN, P. (2011): "Neoliberal Education Restructuring. Dangers and Opportunities of the Present Crisis", Monthly Review.

LÓPEZ GUERRA, S Y CHÁVEZ FLORES, M. (2009): "El fracaso del neoliberalismo y la alternativa educativa latinoamericana", EDUCERE, Ides y Personajes, Vol 13, № 47, pp.1063-1071.

LÓPEZ GUERRA, S Y FLORES, M. (2006): "Las reformas educativas neoliberales en Latinoamérica", Revista Electrónica de Investigación Educativa, Vol. 8, № 1.

LÓPEZ, C. M. (2002): “Comportamiento de las familias ante elección de escuelas y micro-mercados educativos. Estudio del nivel de la Educación General Básica (EGB) en el Partido de Quilmes (Buenos Aires-Argentina)".Tesis de Maestría, Facultad Latinoamericana de Ciencias Sociales. 
MARRERO, A. y CAFFERATTA, G. (2008): "Educación, estado y política en Uruguay: del imaginario estatista al ascenso de los corporativismos (o la nostalgia de la hegemonía)". Revista Iberoamericana de educación, (48), 187-206.

MARTÍNEZ BOOM, A., y NARODOWSKI, M. (1996): Escuela, Historia y Poder. (Miradas desde América Latina). Buenos Aires: Novedades Educativas.

MEZZADRA, F. y RIVAS, A. (2010): "Aportes estatales a la educación de gestión privada en la provincia de Buenos Aires". Documento de Trabajo 51. Buenos Aires: CIPPEC.

MORDUCHOWICZ, A., (ed.) (1999): La educación privada en la Argentina: historia, regulaciones y asignación de recursos públicos. Buenos Aires. Mimeo

MOSCHETTI, M. (2012). "La expansión de la educación privada en Argentina (1994-2010). Un estudio sobre el cuasimonopolio del sistema educativo." Tesis de Maestría, Universidad Torcuato Di Tella.

NARODOWSKI, M. (2002): "Socioeconomic Segregation in the Argentine Education System. School Choice without Vouchers", Compare, Vol. 32, No. 2.

NARODOWSKI, M. (2002a): "Monopolio estatal y elección de escuelas en Argentina". En Nuevas tendencias en Políticas Educativas, ed. Mariano Narodowski, Milagros Nores y Myrian Andrada.

Buenos Aires: Granica.

NARODOWSKI, M. (2008): "School Choice and Quasi-State Monopoly in Education Systems in Latin America: the case of Argentina". En FORSEY, M. . DAVIES, S \& WALFORD, W. (Eds.). The Globalisation of School Choice. Oxford: Symposium Books.

NARODOWSKI, M. (2010): "Cuasi monopolios escolares: lo que el viento nunca se llevó." Educación y Pedagogía 22 (58): 29-36.

NARODOWSKI, M y ALEGRE, S (2013): La persistencia de la exclusión en las escuelas secundarias públicas de Argentina (2000-2011), Documento de trabajo, Universidad Torcuato Di Tella.

NARODOWSKI, M: ALEGRE, S. y VINACUR, T (2014): Los mejores maestros. Mitos, leyendas y realidades. Buenos Aires: Prometeo.

NARODOWSKI, M.,y M. ANDRADA. (2001): "The Privatisation of Education in Argentina." Journal of Education Policy 16 (6): 585-595.

NARODOWSKI, M; NORES, M; (2003): "Searching for "neoliberal" education policies. A comparative

$:: 72::$ analysis of Argentina and Chile", En BALL, S et. al (eds). Crisis and Hope: The Educational Hopscotch of Latin America, London: Routledge.

NARODOWSKI, M y MOSCHETTI, M. (2015): "The growth of private education in Argentina: evidence and explanations", Compare: A Journal of Comparative and International Education 45 (1).

NARODOWSKI, M y MOSCHETTI, M. (2014): "Vuelen Blancas Palomitas. La caída de la matrícula en las escuelas primarias públicas argentinas" Foco Económico. Un blog de economía bastante racional. Disponible en http://focoeconomico.org/2014/07/15/vuelen-blancas-palomitas-la-caida-dela-matricula-en-las-escuelas-primarias-publicas-argentinas/

NARODOWSKI, M; GONZALEZ ROSADA, M; GOTTAU, V y MOSCHETTI, M (2014): School Choice without Vouchers and Socioeconomic Segregation in the City of Buenos Aires, Working Papers Series, Buenos Aires: Universidad Torcuato Di Tella

OSSENBACH SAUTER, G. (2001): "Génesis histórica de los sistemas educativos", Cuadernos de la OEI, No 3 , Madrid.

PUIGGRÓS, A. (1996): "Educación neoliberal y quiebre educativo", Nueva Sociedad, Nro. 146.

PUIGGRÓS, A. (dir.) (1997): Tomo VIII: Dictaduras y Utopías en la historia reciente de la educación argentina (1955-1983). Bs. As: Ed. Galerna.

PUIGGRÓS, A. (2003): Qué pasó en la educación argentina. Buenos Aires: Galerna.

RIELLA, A., \& Andrioli, A. (2004): "El Poder Simbólico de las Gremiales Ganaderos en el Uruguay Contemporáneo". Sociologías, 6(11).

SALTMAN, K. J. (2009): "Putting the Public back in Public Schooling: Public Schools beyond the Corporate Model", De Paul Journal for Social Justice, Vol. 3, №. 1.

SAFORCADA, F., y VASSILIADES, A. (2011): "Education laws in the early 21ST century: from neoliberalism to the post-Washington consensus in South America." Educação \& Sociedade, 32(115), 287-304.

SCIALABBA, A. (2006): "Evaluación de la educación por parte de la opinión pública y su conformidad con la educación pública y privada en la Ciudad de Buenos Aires". Tesis de Maestría, Universidad de San Andrés.

SMALL, D. (2009): "Neoliberalism's Fate: Implications for Education", 37th Annual Conference of ANZCIES. 
FERNÁNDEZ, AGUERRE, T. (2002): "Determinantes sociales e institucionales de la desigualdad educativa en sexto año de educación primaria de Argentina y Uruguay, 1999. Una aproximación mediante un modelo de regresión logística". Revista Mexicana de Investigación Educativa, 7 (16) pp. 501-536.

TORRES, C. A. (2008): "Después de la tormenta neoliberal: La política educativa latinoamericana entre la crítica y la utopía", Revista Iberoamericana de Educación, N. 48.

TORRES, C. A. y PUIGGRÓS, A. (1995): "The State and Public Education in Latin America" Comparative Education Review 39 (1): 8-27.

VON HAYEK, F. (1994): The Road to Serfdom. Chicago: University of Chicago Press.

Recibido el 23 de junio de 2014 Aceptado el 29 de setiembre de 2014 